Brit. J. industr. Med., 1954, 11, 75.

\title{
TUMOURS OF THE URINARY BLADDER IN WORKMEN ENGAGED IN THE MANUFACTURE AND USE OF CERTAIN DYESTUFF INTERMEDIATES IN THE BRITISH CHEMICAL INDUSTRY \\ PART I. THE ROLE OF ANILINE, BENZIDINE, ALPHA-NAPHTHYLAMINE, AND BETA-NAPHTHYLAMINE \\ BY .
}

\author{
R. A. M. CASE, MARJORIE E. HOSKER,* DREVER B. McDONALD, \\ and JOAN T. PEARSON
}

From the Chester Beatty Research Institute, the Institute of Cancer Research, University of London

(RECEIVED FOR PUBLICATION NOVEMBER 4, 1953)

\section{The Scope of the Report}

The genesis, history, and achievements of the Association of British Chemical Manufacturers' research scheme for the investigation of tumour of the urinary bladder in a section of the chemical industry have recently been described in some detail by the Association (1953). The present paper is the result of a five-year field survey of the problem conducted in the factories of, and amongst the workpeople employed by, a group of interested member firms of the Association which had contributed towards the cost of the research. Part I has been written in two sections, the one, in narrative form, is the report proper and does not presuppose any detailed medical or statistical knowledge on the part of the reader ; the other is an appendix where some of the statistical manipulations to which the data have been subjected are set out in full. In Part II, which will be published in this journal shortly, the results relating to auramine or magenta reported herein will be considered in more detail. Both parts have been used as a basis for the recent legislation whereby tumour of the bladder occurring in certain occupations has been prescribed for benefit under the National Insurance (Industrial Injuries) Act (Statutory Instrument. No. 1740, 1953).

It was laid down in the terms of reference that the function of the field survey was to establish whether the manufacture or use of aniline, benzidine,

\footnotetext{
* Sometime Royal Cancer Hospital Research Scholar.
}

$\alpha$-naphthylamine or $\beta$-naphthylamine could be shown to produce tumours of the urinary bladder in men so engaged. Accordingly, the scope of this report has been limited to this topic, with but minor digressions to consider other possible causative substances. Furthermore, many medical aspects of the problem have been ignored or simplified. Both cancer of the bladder and papilloma of the bladder have been considered as an entity, after a purely statistical investigation to see that they could be so considered, and treatment has been ignored.

\section{Historical}

In 1895 the German surgeon Rehn reported what he considered to be an undue incidence of bladder tumours in a group of men employed in the manufacture of fuchsine (magenta), and he concluded that aniline was the most suspicious of the substances used in this process. From this supposition the term " aniline tumour of the bladder" stemmed, and has since become current in medical textbooks. Since this time there have been numerous reports from Great Britain, Germany, Japan, Switzerland, France, Italy, and America on this topic, and unanimity of opinion has been reached only about $\beta$-naphthylamine, which has been generally accepted as a cause of human bladder cancer. $\alpha$-Naphthylamine has been suggested as a possible cause by some authorities, and strenuously denied this status by others. Those who believe that $\alpha$-naphthylamine is dangerous seem to have tacitly accepted that the substance acts 
because it always contains a small proportion of $\beta$-naphthylamine. Benzidine has also been a subject of controversy, and, though American opinion on the whole seems to favour the theory that this substance is not a cause of bladder tumour, the opposite view seems to be held in Europe. There never appears to have been much evidence to implicate aniline as such, although the original observations on the manufacture of magenta were certainly valid.

Hueper, Wiley, and Wolfe (1938) conclusively showed that $\beta$-naphthylamine, in its commercially available form, caused bladder tumours in dogs, and Bonser (1943) confirmed these observations using a partially purified product. No convincing evidence of induction of bladder tumours by aniline, $\alpha$-naphthylamine or benzidine in dogs or other animals has yet been produced although Baker (1950) claims bladder tumours in mice from $3: 3^{\prime}$ dihydroxy $4: 4^{\prime}$ diaminodiphenyl which he considered to be a metabolite of benzidine ; and Spitz, Maguigan, and Dobriner (1950) have induced tumours in other situations with benzidine itself. The evidence that pure $\beta$-naphthylamine or one of its metabolites are the only active carcinogens concerned in the production of tumours by this substance is not yet completely convincing, despite the work of Bonser, Clayson, and Jull (1951) who induced bladder tumours in mice by implanting paraffin wax pellets containing 2-amino-1-naphthol into the bladder, since Case and Pearson (1952) have demonstrated carcinogenic impurities in commercial $\beta$-naphthylamine and in what had previously been considered as " pure" $\beta$-naphthylamine. For the purposes of this report, therefore, the terms aniline, benzidine, and naphthylamine will mean these substances as encountered in industrial practice, and will not mean these substances as pure chemicals in the sense that an organic chemist might use such a term.

Goldblatt (1947) and Müller (1949) have reviewed the risk in industry at length, and Bonser (1947) has discussed the experimental aspects of the problem.

\section{Sources of Information}

The following sources of information have been available :-

Cases of Bladder Tumour in the Industry.-This is found in cases reported by firms; cases found in hospital records and confirmed by firms; cases found in hospital records and confirmed by the patient or near relative; cases found from an examination of death certificates where the chemical industry was mentioned as the occupation of the deceased ; cases found from a cross-check between a nominal roll of persons known to be at risk and all the names collected by the means listed above ; cases found in coroners' records.

The Populations at Risk.-The firms participating in the scheme were asked to provide a nominal roll of all workers known to have had any contact with aniline, benzidine, $\alpha$-naphthylamine or $\beta$-naphthylamine, stating the age of the worker and the dates between which he was exposed to these substances. Twenty-one firms complied with this request to the best of their ability, and a reasonably complete nominal roll from 1920 was compiled.

Natural History of the Incidence of the Disease in Males in General Population.-All death certificates mentioning bladder tumour for males dying in England and Wales between the years 1921 and 1949 were available. Many hospitals collaborated by allowing the use of their records for recent years.

Processes and Local Conditions.-All the participating firms cooperated by allowing complete facilities to inspect processes, and by collecting works-history data of cases known to have occurred in their factories.

Many other firms, members of the A.B.C.M. but not participating in the scheme, helped by giving information about ex-employees who developed bladder tumour.

\section{The Nature of the Problem}

Tumour of the urinary bladder occurs in both sexes in the general population. It is more frequent in males (about 2.5 males to 1 female) and is predominantly a disease appearing in the later years of life. Only $14 \%$ of all adult male deaths in England and Wales from the disease occur before the age of 55. Although the disease may be divided roughly into papilloma and cancer of the bladder, death certificates show that at death $88 \%$ of the deaths from bladder tumour are attributed to cancer and $12 \%$ to papilloma or benign tumour. This figure applies to all male deaths in England and Wales. In the cases found in the chemical industry this proportion is $94 \%$ cancer and $6 \%$ papilloma. This difference is of no statistical significance ; in other words, there is no special tendency for industrial tumours to be either more or less predominantly papilloma than non-industrial ones, as judged from death certificate data. The disorder, tumour of the bladder, must be regarded as a killing disease ; only $20 \%$ of all cases found by this survey in the dyestuffs industry survived more than 10 years from the first recognition of the disease. Since, as will be shown 
later, the age of onset of the industrial form of the disease depends almost entirely on the age of entry into the relevant occupations, this high case mortality is serious. All patients who develop bladder tumour are not, of course, eventually certified as having a bladder tumour at death. Out of 819 cases notified by hospitals and known to be dead, $666(81.3 \%)$ had a mention of bladder tumour on the death certificate.

\section{Limitations of the Statistical Analysis}

The accuracy of any statistical analysis is limited by the accuracy of the information upon which it is based. In the present study it often happened that the only data now in existence are those provided by the participating firms, and such data were not recorded for this purpose. Although such information has been examined most carefully as to its validity before incorporating it in this report, and where corroborative evidence, such as coroners' and factory inspectors' reports, was available, such additional information was always sought, the underlying possibility of inaccuracy must be borne in mind in interpreting the results.

There will be a tendency for the information to become less reliable as the period for which it is collected becomes more remote, and, as with some other occupational hazards which also occur in the general population, some of the cases which should properly have been assigned to occupational causes will have escaped notice as such, especially in areas of the country where medical opinion has not been focused on the hazard.

In the statistical analysis, only cases appearing on the nominal roll are used, and care was taken to ensure that no cases were placed on the nominal roll solely because it was known that they had developed a tumour. Thus, although in more remote times the nominal roll itself is too small, the tendency will always be to underestimate the industrial hazard through failing to trace all cases.

Certain conclusions drawn have only a statistical significance, with which implication the word is used in this report, therefore extrapolation from these conclusions should only be made with caution. For example, it will be shown that there is a slightly increased tendency for men entering the hazardous occupation at a more advanced age to develop tumours than for men entering at an earlier age. This does not necessarily imply any biological difference in susceptibility since, for instance, it could be explained on the hypothesis that older entrants are given more responsible jobs which would necessarily involve more exposure to the dangerous material.
Another example of the limitation of the term "significant" occurs where the statistical analysis of the data shows that the induction time* is independent of the exposure time. This does not mean that such a conclusion would be reached by animal experiments, or even by a very detailed analysis of short exposure times, but that within the rather coarse groupings of exposure times and induction times used, the two times are independent. Therefore it is legitimate to use the observed shape of the distribution of induction times as a basis for analysing the expected rate of appearance of cases.

The scope of the analysis is limited severely by the small number of cases that can be expected to occur since 1945, a date when, in accordance with earlier appreciation of the risk, certain sweeping changes in plant design were introduced. It is quite impossible at this stage to predict what effects these changes may have, and it will be realized that the slight reduction of risk noted in the post-1930 period is a mean value, and does not necessarily take into account the progressive results of these changes, which will have to await the judgment of posterity. Another limitation is the lack of knowledge of the relative importance of the different routes by which the dangerous substances may enter the human body, and of precise data about the operative concentrations of the substances met with and the amounts absorbed and eliminated.

\section{Results}

In all, by February 1, 1952, 455 cases of bladder tumour had been found in the British chemical industry. Four hundred and forty-four of these cases were found in and after 1921, the first year in which death certificates were available for a systematic search. Table 1 shows the distribution of these cases within the industry. Of the 341 cases occurring in employees of the member firms participating in the scheme, $298(87.4 \%)$ had had contact with benzidine, $\beta$-naphthylamine, or $\alpha$-naphthylamine, and only $32(9 \cdot 4 \%)$ were known not to have had such contact. It is necessary, as a starting point, to assess whether or not these 341 cases are more than could reasonably be expected by chance, on the assumption that the industry is exposed to only the same risk of developing bladder tumour as the general population. To do this it is necessary to form an estimate of the number of cases expected on this assumption, and this requires a knowledge of the population at risk. The nominal roll provides such knowledge in some detail, and of the 311 cases

* The length of time between first exposure to risk and the recognition of the tumour. 
TABLE 1

THE DISTRIBUTION OF CASES OF BLADDER TUMOUR WITHIN THE CHEMICAL INDUSTRY

\begin{tabular}{|c|c|c|c|c|c|c|c|c|c|c|c|c|c|c|c|c|c|c|c|c|}
\hline \multirow{3}{*}{$\begin{array}{l}\text { Date } \\
\text { Group }\end{array}$} & \multicolumn{8}{|c|}{ Member Firms Investigated } & \multicolumn{10}{|c|}{ All Others } & \multirow{2}{*}{\multicolumn{2}{|c|}{$\begin{array}{l}\text { Total } \\
\text { All } \\
\text { Groups }\end{array}$}} \\
\hline & \multicolumn{2}{|c|}{$\begin{array}{c}\text { Contacts } \\
\text { Include } \\
\alpha \text {-Naph- } \\
\text { thylamine, } \\
\beta-N a p h- \\
\text { thylamine, } \\
\text { or } \\
\text { Benzidine }\end{array}$} & \multicolumn{2}{|c|}{$\begin{array}{l}\text { Contacts } \\
\text { Known } \\
\text { not to } \\
\text { Include } \alpha \text { - } \\
\text { Naphthyl- } \\
\text { amine, } \beta- \\
\text { Naphthyl- } \\
\text { amine or } \\
\text { Benzidine }\end{array}$} & \multicolumn{2}{|c|}{$\begin{array}{c}\text { Contacts } \\
\text { not } \\
\text { Known }\end{array}$} & \multicolumn{2}{|c|}{ Total } & \multicolumn{2}{|c|}{$\begin{array}{c}\text { Employers } \\
\text { not } \\
\text { Known }\end{array}$} & \multicolumn{2}{|c|}{$\begin{array}{c}\text { Member } \\
\text { Firms not } \\
\text { partici- } \\
\text { pating in } \\
\text { Scheme } \\
\text { and not } \\
\text { Investi- } \\
\text { gated }\end{array}$} & \multicolumn{2}{|c|}{$\begin{array}{l}\text { Existing } \\
\text { Firms not } \\
\text { Members } \\
\text { of } \\
\text { A.B.C.M. }\end{array}$} & \multicolumn{2}{|c|}{$\begin{array}{l}\text { Firms no } \\
\text { Longer } \\
\text { Existing }\end{array}$} & \multicolumn{2}{|c|}{ Total } & & \\
\hline & Alive & Dead & Alive & Dead & Alive & Dead & Alive & Dead & Alive & Dead & Alive & Dead & Alive & Dead & Alive & Dead & Alive & Dead & Alive & Dead \\
\hline Before 1900 & 0 & $\mathbf{0}$ & $\mathbf{0}$ & $\mathbf{0}$ & 0 & 0 & 0 & $\mathbf{0}$ & 0 & 1 & 0 & 0 & 0 & $\mathbf{0}$ & $\mathbf{0}$ & 0 & $\mathbf{0}$ & 1 & 0 & 1 \\
\hline $1900-1904$ & $\mathbf{0}$ & $\mathbf{0}$ & 0 & 1 & 0 & 0 & 0 & 1 & 0 & 1 & 0 & 0 & 0 & 0 & 0 & 2 & 0 & 3 & 0 & 4 \\
\hline $1905-1909$ & 0 & 1 & 0 & 0 & 0 & 0 & 0 & 1 & 0 & 0 & $\mathbf{0}$ & 0 & 0 & 0 & 0 & 1 & 0 & 1 & 0 & 2 \\
\hline 1910-1914 & 0 & 0 & 0 & 0 & 0 & 0 & 0 & 0 & $\mathbf{0}$ & 1 & 0 & 0 & 0 & 0 & 0 & 0 & 0 & 1 & $\mathbf{0}$ & 1 \\
\hline 1915-1919 & 0 & 1 & 0 & 0 & 0 & 0 & 0 & 1 & 0 & 1 & 0 & 0 & 0 & 0 & 0 & 1 & 0 & 2 & 0 & 3 \\
\hline $1920-1924$ & 0 & 3 & 0 & 0 & 0 & 1 & 0 & 4 & 0 & 8 & $1^{*}$ & 3 & 0 & 1 & 0 & 0 & $1^{*}$ & 12 & $1^{*}$ & 16 \\
\hline $1925-1929$ & 2 & 13 & 0 & 5 & 0 & 0 & 2 & 18 & 0 & 9 & 0 & 5 & 0 & 1 & $1^{*}$ & 3 & $1^{*}$ & 18 & $3 *$ & 36 \\
\hline $1930-1934$ & 3 & 18 & $2 *$ & 2 & 0 & 1 & $5 *$ & 21 & 0 & 11 & 0 & 6 & 0 & 0 & 0 & 1 & 0 & 18 & $5^{*}$ & 39 \\
\hline $1935-1939$ & 14 & 24 & 4 & 2 & 0 & 1 & 18 & 27 & 0 & 12 & 0 & 7 & 0 & 0 & 0 & 1 & 0 & 20 & 18 & 47 \\
\hline $1940-1944$ & 22 & 50 & 5 & 2 & 3 & 2 & 30 & 54 & 0 & 12 & 0 & 5 & 0 & 0 & 0 & 0 & 0 & 17 & 30 & 71 \\
\hline 1945-1949 & 50 & 50 & 5 & 3 & 0 & 2 & 55 & 55 & 0 & 8 & 1 & 8 & 1 & 0 & 0 & 0 & 2 & 16 & 57 & 71 \\
\hline$\ddagger 1950-$ & 31 & 13 & 1 & 0 & 1 & 0 & 33 & 13 & 0 & 0 & 0 & 0 & 0 & 0 & 0 & 0 & 0 & 0 & 33 & 13 \\
\hline Total & 122 & 176 & 17 & 15 & 4 & 7 & 143 & 198 & 0 & 65 & 2 & 34 & 1 & 2 & 1 & 9 & 4 & 110 & 147 & 308 \\
\hline Total & 29 & & 32 & 2 & 1 & 1 & 34 & 41 & & 65 & 3 & & 3 & 3 & 1 & 10 & 11 & 14 & 45 & 55 \\
\hline $\begin{array}{l}\text { Contacts } \\
\text { include only } \\
\alpha \text {-naphthylami } \\
\text { of these three } \\
\text { substances } \\
\qquad 28\end{array}$ & $\begin{array}{l}\mathrm{C} \\
\text { in } \\
\beta \\
\text { of } \\
\text { su }\end{array}$ & $\begin{array}{l}\text { I } \\
\text { ontacts } \\
\text { aclude c } \\
\text {-naphth } \\
\text { f these } \\
\text { ubstanc }\end{array}$ & $\begin{array}{l}\text { is } \\
\text { only } \\
\text { thylami } \\
\text { three } \\
\text { ces }\end{array}$ & ine & $\begin{array}{l}\text { Contact } \\
\text { include } \\
\text { benzidi } \\
\text { these th } \\
\text { substan }\end{array}$ & $\begin{array}{l}\text { ts } \\
\text { only } \\
\text { ine of } \\
\text { hree } \\
\text { ices }\end{array}$ & $\begin{array}{l}\text { Con } \\
\text { inclu } \\
\text { or m } \\
\text { these } \\
\text { subs }\end{array}$ & $\begin{array}{l}\text { tacts } \\
\text { ude two } \\
\text { nore of } \\
\text { e three } \\
\text { stances } \\
173\end{array}$ & & & & Key : & $\begin{array}{r}* \mathrm{Ca} \\
\mathrm{d} \\
+\mathrm{De} \\
\mathrm{u} \\
+195 \\
\mathrm{a}\end{array}$ & $\begin{array}{l}\text { ase wh } \\
\text { died. } \\
\text { eath ce } \\
\text { until } 19 \\
50 \text { an } \\
\text { availab }\end{array}$ & $\begin{array}{l}\text { nere it } \\
\text { ertifica } \\
921 \text {. } \\
\text { hd sub } \\
\text { ble at d }\end{array}$ & $\begin{array}{l}\text { is unl } \\
\text { tes no } \\
\text { bsequen } \\
\text { date of }\end{array}$ & $\begin{array}{l}\text { known } \\
\text { searc } \\
\text { at deat } \\
\text { analysi }\end{array}$ & $\begin{array}{l}\text { if the } \\
\text { ched } s \\
\text { th cer } \\
\text { is. }\end{array}$ & $\begin{array}{l}\text { e patie } \\
\text { systema } \\
\text { rtificate }\end{array}$ & $\begin{array}{l}\text { nt has } \\
\text { atically } \\
\text { es not }\end{array}$ \\
\hline & & & & $\begin{array}{l}\text { Co } \\
\text { inc } \\
\text { ani } \\
\text { (als } \\
\text { in } \\
\text { but } \\
\text { ma }\end{array}$ & $\begin{array}{l}\text { ontacts } \\
\text { lude } \\
\text { iline } \\
\text { so aura } \\
\text { two cas } \\
\text { t not } \\
\text { agenta }\end{array}$ & $\begin{array}{l}\text { amine } \\
\text { ses) }\end{array}$ & $\begin{array}{l}\text { Con } \\
\text { incly } \\
\text { mag }\end{array}$ & $\begin{array}{l}\text { ude } \\
\text { genta } \\
9\end{array}$ & & $\begin{array}{l}\text { Conta } \\
\text { includ } \\
\text { auran } \\
\text { but } n \\
\text { anilin } \\
4\end{array}$ & $\begin{array}{l}\text { tacts } \\
\text { ide } \\
\text { mine } \\
\text { not } \\
\text { ne }\end{array}$ & & $\begin{array}{l}\text { Conta } \\
\text { includ } \\
\text { substa } \\
\text { not m } \\
\text { here }\end{array}$ & $\begin{array}{l}\text { acts } \\
\text { de only } \\
\text { ances } \\
\text { ention } \\
15\end{array}$ & ned & & & & & \\
\hline
\end{tabular}

which had had contact with aniline, benzidine, $\beta$-naphthylamine, or $\alpha$-naphthylamine, 262 were persons whose names appeared on the nominal roll. This figure of 311 consists of 298 cases with contact with benzidine, $\alpha$-naphthylamine, or $\beta$-naphthylamine, four with contact with aniline only, and nine with contact only with magenta.

A qualification for the nominal roll was that the persons must have been employed in the chemical industry for more than six months, though not necessarily in contact with the suspected substances. 
the 4,622 men if no special risk were attached to their work, but it is possible to form a reasonable estimate of the number of death certificates mentioning tumour of the bladder which would be expected on this assumption (Case, 1953a, b). This expected number is between 3 and 5 for the 4,622 men, all due allowance being made for the age of the men and their date of entry into the work with the four substances mentioned; and the number of death certificates mentioning tumour of the bladder found amongst the 262 cases whose names appear on the nominal roll was 127 . There is therefore no doubt that a risk of dying of tumour of the bladder exists amongst that group of people who have had contact with aniline, benzidine, $\beta$-naphthylamine, or $\alpha$-naphthylamine. In this group, that is those men who are known to have had contact with any of the four substances named and have been employed in the chemical industry for more than six months, even though their period of contact with any of the four substances was not necessarily six months, the data indicate that the overall risk of dying of bladder tumour is approximately 30 times that of the general population.

\section{The Localization of the Risk within the Industry}

It is now necessary to examine this group more carefully to see where the risk lies, and to see which of the specific substances mentioned can be implicated and which exonerated as causative agents. It seems very unlikely that the employees of the 21 participating firms could fairly be regarded as having equal chances of exposure to the suspected substances, but statistical analysis is hampered because no actual measure of exposure exists. It was therefore decided to consider the nominal roll in three sections, an arbitrary classification being made as follows :-

Group I.-The nominal roll of those firms which manufacture any one or more of the substances, aniline, benzidine, $\alpha$-naphthylamine, $\beta$-naphthylamine ; it will of course consist of men exposed in both manufacture and use, since these firms also use these substances. This group consists of 3,198 men.

Group II.-The nominal roll of those firms which use but do not manufacture any of these substances, excluding those firms whose use is confined to the purification of the substances for sale as fine chemicals. This group consists of 1,275 men.

Group III.-The nominal roll of those firms which only purify any of these substances : this group consists of 149 men.
The distribution of the 311 cases of bladder tumour which had had contact with one or more of these four substances, with the number of death certificates mentioning tumour of the bladder expected and found, is shown for each group in Table 2 (Rank 9), and it is apparent that Groups I and II have an undoubted occupational risk of dying with bladder tumour. The one death in Group III is suspicious considering the low expectation of such an event.

It is convenient here to depart from a logical sequence of development, and to discuss an indication the justification for which will be dealt with more fully later. This is that the age of death was 51 in the one dead case in Group III, and that the age of onset was 29 in the other case. Both these ages are low compared with the most frequent age of death (65-70 years) or onset (60-70 years) found for bladder tumour in the general population and this fact lends weight to the suspicion that an occupational risk is operating.

Thus we may say that the occupational hazard at work is most intense in Group I, less so, but still definitely present in Group II, and probably still operating in Group III.

\section{The Localization of the Risk to Particular Substances}

It is now necessary to consider the evidence for the implication of each of these substances as a cause of bladder tumour, again using the death certificate criterion since this is the most precise measure available.

Aniline.-This is considered separately as a special case, since, as will be shown, the effect of the substance is different from that of the remaining three substances.

When the compilation of the nominal roll by member firms was first requested, the possible importance of magenta was not realized, but all manufacturers of magenta are automatically qualified for the nominal roll in virtue of the fact that they must handle aniline, and it is possible to divide the aniline nominal roll into two sections. (1) That derived from firms where it is known that magenta is not manufactured; (2) that derived from firms where it is known that magenta is manufactured. Only a small proportion of the names on the second list will have been exposed to the manufacture of magenta. Ranks 1, 2, and 3 of Table 2 show the tumour cases and the expectation of death certificates from the aniline nominal roll divided in this way for the three groups of firms. It can be seen from these figures that there is not a sufficient excess of certificates found over certificates expected to 
TABLE 2

THE NUMBER OF DEATH CERTIFICATES EXPECTED IF NO SPECIAL RISK WERE OPERATING AND THE NUMBER OF CASES AND DEATH CERTIFICATES FOUND FOR THE VARIOUS EXPOSURE CLASSES

\begin{tabular}{|c|c|c|c|c|c|c|c|c|c|c|c|}
\hline \multirow[b]{2}{*}{ Rank } & \multirow[b]{2}{*}{ Class } & \multirow[b]{2}{*}{ Group } & \multirow{2}{*}{$\begin{array}{l}\text { Total } \\
\text { No. of } \\
\text { Cases } \\
\text { Found }\end{array}$} & \multicolumn{3}{|c|}{ Cases on Nominal Roll } & \multirow{2}{*}{\begin{tabular}{|c|} 
Cases on \\
Nominal \\
Roll \\
where \\
Deaath \\
Certificate \\
Mentions \\
Bladder \\
Tumour \\
\end{tabular}} & \multirow{2}{*}{$\begin{array}{c}\text { Expected } \\
\text { No. of } \\
\text { Such } \\
\text { Cases }\end{array}$} & \multirow{2}{*}{$\begin{array}{c}\% \text { of } \\
\text { Expected } \\
\text { No. } \\
\text { Derived } \\
\text { from In- } \\
\text { complete } \\
\text { Data }\end{array}$} & \\
\hline & & & & Total & Alive & Dead & & & & Differen & ice \\
\hline \multirow[t]{2}{*}{1} & \multirow[t]{2}{*}{$\begin{array}{c}\text { Aniline without } \\
\text { magenta contact }\end{array}$} & $\begin{array}{c}\text { I } \\
\text { III }\end{array}$ & $\begin{array}{l}4 \\
0 \\
0\end{array}$ & $\begin{array}{l}4^{* *} \\
0 \\
0\end{array}$ & $\begin{array}{l}2^{*} \\
0 \\
0\end{array}$ & $\begin{array}{l}2^{*} \\
0 \\
0\end{array}$ & $\begin{array}{l}1 \\
0 \\
0\end{array}$ & $\begin{array}{l}0.30 \\
0.23 \\
0.01\end{array}$ & $35 \cdot 8$ & $\begin{array}{l}\text { None } \\
\text { None } \\
\text { None }\end{array}$ & $\begin{array}{l}>0 \cdot 1 \\
>0 \cdot 1 \\
>0 \cdot 1\end{array}$ \\
\hline & & All & 4 & $4^{* *}$ & $2^{*}$ & $2^{*}$ & 1 & $0 \cdot 54$ & & None & $>0.1$ \\
\hline \multirow[t]{2}{*}{2} & \multirow[t]{2}{*}{$\begin{array}{l}\text { Aniline with pos- } \\
\text { sible magenta } \\
\text { contact }\end{array}$} & $\begin{array}{r}\text { I } \\
\text { II } \\
\text { III }\end{array}$ & $\begin{array}{l}8 \\
1 \\
0\end{array}$ & $\begin{array}{l}5 \\
1 \\
0\end{array}$ & $\begin{array}{l}3 \\
0 \\
0\end{array}$ & $\begin{array}{l}2 \\
1 \\
0\end{array}$ & $\begin{array}{l}2 \\
1 \\
0\end{array}$ & $\begin{array}{l}0.30 \\
0.05 \\
0.00\end{array}$ & $15 \cdot 6$ & $\begin{array}{l}\text { Suspicious } \\
\text { None } \\
\text { None }\end{array}$ & $\begin{aligned} & 0.025 \\
> & 0.1 \\
> & 0.9\end{aligned}$ \\
\hline & & All & 9 & 6 & 3 & 3 & 3 & 0.35 & & Significant & $<0.02$ \\
\hline \multirow[t]{2}{*}{3} & \multirow[t]{2}{*}{ All aniline } & $\begin{array}{r}\text { I } \\
\text { II } \\
\text { III }\end{array}$ & $\begin{array}{r}12 \\
1 \\
0\end{array}$ & $\begin{array}{l}9^{* * *} \\
1 \\
0 \\
\end{array}$ & $\begin{array}{l}5^{*} \\
0 \\
0 \\
\end{array}$ & $\begin{array}{l}4^{*} \\
1 \\
0\end{array}$ & $\begin{array}{l}3 \\
1 \\
0\end{array}$ & $\begin{array}{l}0 \cdot 60 \\
0 \cdot 28 \\
0 \cdot 01\end{array}$ & $20 \cdot 3$ & $\begin{array}{l}\text { Suspicious } \\
\text { None } \\
\text { None }\end{array}$ & $\begin{aligned} & 0.025 \\
< & 0.1 \\
< & 0.1\end{aligned}$ \\
\hline & & All & 13 & $10^{* *}$ & $5^{*}$ & $5^{*}$ & 4 & $0 \cdot 89$ & & Suspicious & 0.025 \\
\hline \multirow[t]{2}{*}{4} & \multirow[t]{2}{*}{ Benzidine } & II & $\begin{array}{r}38 \\
0 \\
0 \\
\end{array}$ & $\begin{array}{r}34 \\
0 \\
0 \\
\end{array}$ & $\begin{array}{r}21 \\
0 \\
0\end{array}$ & $\begin{array}{r}13 \\
0 \\
0 \\
\end{array}$ & $\begin{array}{r}10 \\
0 \\
0\end{array}$ & $\begin{array}{l}0.54 \\
0 \cdot 17 \\
0.01\end{array}$ & $3 \cdot 7$ & $\begin{array}{l}\text { Very high } \\
\text { None } \\
\text { None }\end{array}$ & $\begin{array}{l}<0.001 \\
>0.1 \\
>0.1\end{array}$ \\
\hline & & All & 38 & 34 & 21 & 13 & 10 & 0.72 & & Very high & $<0.001$ \\
\hline \multirow[t]{2}{*}{5} & \multirow[t]{2}{*}{$\alpha$-Naphthylamine } & $\begin{array}{l}\text { I } \\
\text { III } \\
\text { III }\end{array}$ & $\begin{array}{r}28 \\
0 \\
0\end{array}$ & $\begin{array}{r}19 \\
0 \\
0\end{array}$ & $\begin{array}{r}13 \\
0 \\
0\end{array}$ & $\begin{array}{l}6 \\
0 \\
0 \\
\end{array}$ & $\begin{array}{l}6 \\
0 \\
0 \\
\end{array}$ & $\begin{array}{l}0.66 \\
0.04 \\
0.00\end{array}$ & $3 \cdot 2$ & $\begin{array}{l}\text { High } \\
\text { None } \\
\text { None }\end{array}$ & $\begin{aligned} & 0.005 \\
&> 0.1 \\
&> 0.9 \\
&\end{aligned}$ \\
\hline & & All & 28 & 19 & 13 & 6 & 6 & $0 \cdot 70$ & & High & $<0.005$ \\
\hline \multirow[t]{2}{*}{6} & \multirow[t]{2}{*}{$\beta$-Naphthylamine } & $\begin{array}{r}\text { II } \\
\text { III } \\
\text { III }\end{array}$ & $\begin{array}{r}59 \\
0 \\
0 \\
\end{array}$ & $\begin{array}{r}55 \\
0 \\
0 \\
\end{array}$ & $\begin{array}{r}28 \\
0 \\
0 \\
\end{array}$ & $\begin{array}{r}27 \\
0 \\
0 \\
\end{array}$ & $\begin{array}{r}26 \\
0 \\
0 \\
\end{array}$ & $\begin{array}{l}0.30 \\
0.00 \\
0.00 \\
\end{array}$ & $4 \cdot 1$ & $\begin{array}{l}\text { Very high } \\
\text { None } \\
\text { None }\end{array}$ & $\begin{array}{l}<0.001 \\
>0.9 \\
>0.9 \\
\end{array}$ \\
\hline & & All & 59 & 55 & 28 & 27 & 26 & 0.30 & & Very high & $<0.001$ \\
\hline \multirow[t]{2}{*}{7} & \multirow[t]{2}{*}{ Mixed Exposures } & $\begin{array}{r}\text { II } \\
\text { III }\end{array}$ & $\begin{array}{r}162 \\
9 \\
2\end{array}$ & $\begin{array}{r}135 \\
7 \\
2\end{array}$ & $\begin{array}{r}50 \\
0 \\
1\end{array}$ & $\begin{array}{r}85 \\
7 \\
1\end{array}$ & $\begin{array}{r}75 \\
5 \\
1\end{array}$ & $\begin{array}{l}1 \cdot 15 \\
0.32 \\
0.006\end{array}$ & $13 \cdot 5$ & $\begin{array}{l}\text { Very high } \\
\text { High } \\
\text { Significant }\end{array}$ & $\begin{array}{r}<0.001 \\
<0.005 \\
0.005\end{array}$ \\
\hline & & All & 173 & 144 & 51 & 93 & 81 & 1.48 & & Very high & $<0.001$ \\
\hline \multirow[t]{2}{*}{8} & \multirow[t]{2}{*}{$\begin{array}{l}\text { All classes, exclud- } \\
\text { ing aniline }\end{array}$} & $\begin{array}{r}\text { II } \\
\text { III }\end{array}$ & $\begin{array}{r}287 \\
9 \\
2 \\
\end{array}$ & $\begin{array}{r}243 \\
7 \\
2 \\
\end{array}$ & $\begin{array}{r}112 \\
0 \\
1 \\
\end{array}$ & $\begin{array}{r}131 \\
7 \\
1 \\
\end{array}$ & $\begin{array}{r}117 \\
5 \\
1 \\
\end{array}$ & $\begin{array}{l}2.65 \\
0.53 \\
0.02 \\
\end{array}$ & $7 \cdot 3$ & $\begin{array}{l}\text { Very high } \\
\text { High } \\
\text { Suspicious }\end{array}$ & $\begin{array}{r}<0.001 \\
<0.005 \\
0.025 \\
\end{array}$ \\
\hline & & All & 298 & 252 & 113 & 139 & 123 & $3 \cdot 20$ & & Very high & $<0.001$ \\
\hline \multirow[t]{2}{*}{9} & \multirow[t]{2}{*}{ All classes } & $\begin{array}{r}\text { II } \\
\text { II } \\
\text { III } \\
\end{array}$ & $\begin{array}{r}299 \\
10 \\
2\end{array}$ & $\begin{array}{r}252 \\
8 \\
2\end{array}$ & $\begin{array}{r}117 \\
0 \\
1 \\
\end{array}$ & $\begin{array}{r}135 \\
8 \\
1 \\
\end{array}$ & $\begin{array}{r}120 \\
6 \\
1 \\
\end{array}$ & $\begin{array}{l}3.25 \\
0.81 \\
0.03 \\
\end{array}$ & $9 \cdot 3$ & $\begin{array}{l}\text { Very high } \\
\text { High } \\
\text { Suspicious }\end{array}$ & $\begin{array}{r}<0.001 \\
<0.005 \\
0.025\end{array}$ \\
\hline & & All & 311 & 262 & 118 & 144 & 127 & 4.09 & & Very high & $<0.001$ \\
\hline
\end{tabular}

* also manufacturer of auramine.

warrant saying that aniline, as manufactured or used between 1915 and 1950, is a cause of bladder tumour.

Two other points require mention. (1) While, as the figures stand, there is only just enough excess of death certificates found over death certificates expected to be statistically significant in the magenta group, the whole picture is more strongly suggestive that magenta may be dangerous, since it is known that the nominal roll for the magenta group is 
amine, or $\beta$-naphthylamine, can now be allocated to contact with that other substance only.

$\alpha$-Naphthylamine, $\beta$-Naphthylamine, and Benzidine.-The remainder of the 311 cases which had had contact with one of the four substances mentioned above can be subdivided into the following exposure classes:-(1) Those who have had contact with benzidine only of the three substances. (2) Those who have had contact with $\alpha$-naphthylamine only of the three substances. (3) Those who have had contact with $\beta$-naphthylamine only of the three substances. (4) Those who have had a mixed contact with two or more of the three substances.

Ranks 4 to 8 of Table 2 show the tumour cases, the number with bladder tumour death certificates, and the number of death certificates expected if no special risk existed for these exposure classes and for the three groups of firms. These data show that benzidine, $\alpha$-naphthylamine, and $\beta$-naphthylamine are associated with an increased death certification rate from tumour of the bladder. It will also be seen that only $2.6 \%$ of all the cases with bladder tumour death certificates would be expected to be of natural occurrence. If this ratio is even approximately valid for the remainder, it means that the whole group of cases can be considered as consisting of virtually only occupational tumours, and accordingly will be so considered.

It is necessary to examine the works history of the cases to see what types of job give rise to this risk. The nominal roll does not give full occupational details, so that differential rates cannot be obtained. The job-analysis of the 298 cases which had contact with one or more of the three substances under consideration is set out in Table 3 for each exposure class of substance and for each group of firms, and an inspection of Table 3 shows that the substances benzidine, $\alpha$-naphthylamine, and $\beta$-naphthylamine can cause bladder tumour in workers engaged in

TABLE 3

JOB ANALYSIS

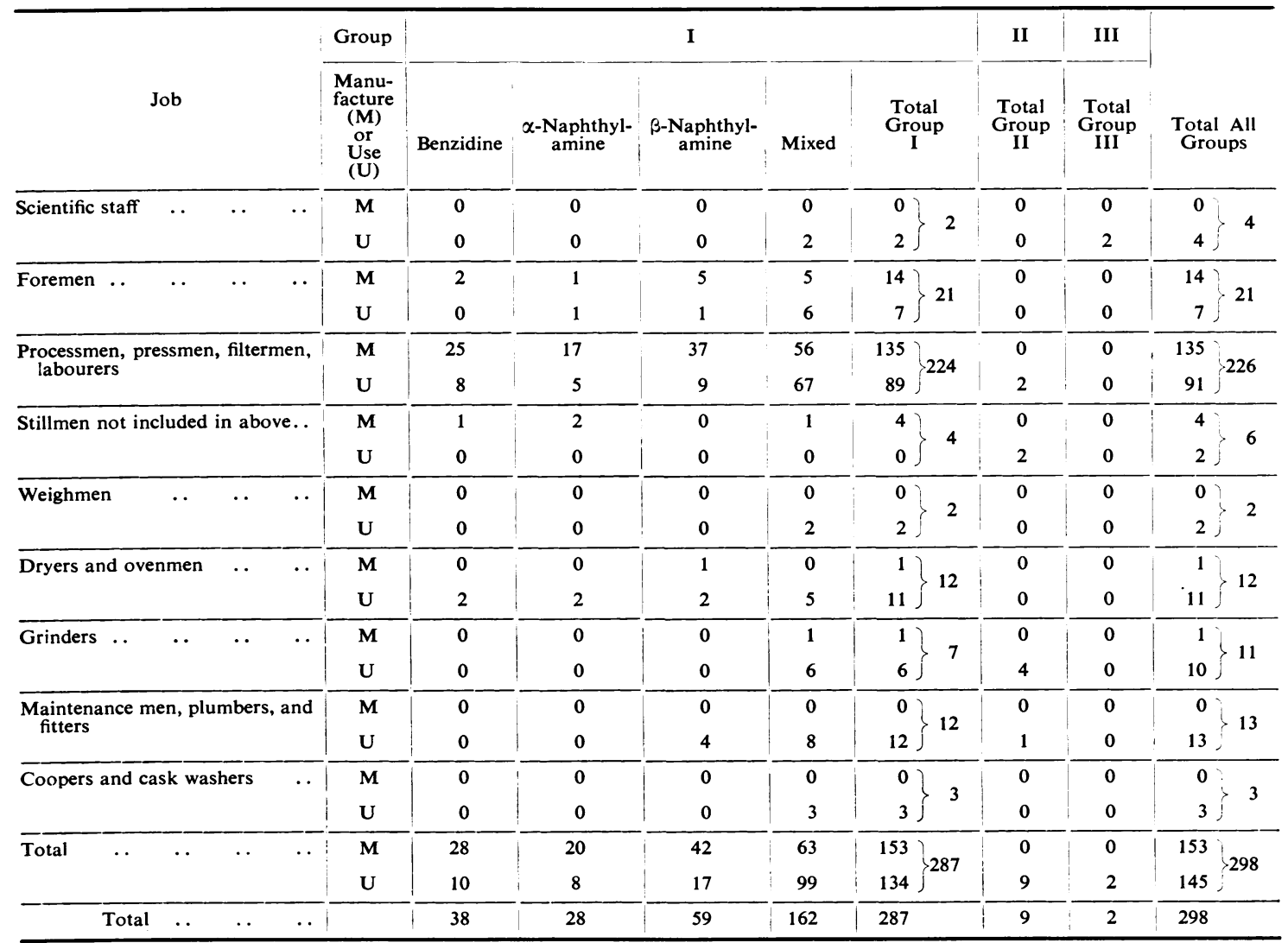


either the manufacture or use of the material, and that the risk spreads through a wide variety of methods of coming into contact with the substances. A multiplicity of processes is covered by the jobs mentioned in the table, the extent of which is indicated by the following list.

Cases have been caused by the manufacture of both naphthylamines, their distillation, their flaking or stoving, their sulphonation, and the manufacture of sodium naphthionate; the manufacture and use of the free bases, their hydrochlorides, and their sulphates.

The manufacture of benzidine and its isolation as the base; the monohydrochloride, the dihydrochloride, and the sulphate, the use of benzidine and its salts.

The manufacture, drying, and grinding of finished colour prepared from the naphthylamines and benzidine, and the hand mixing of finished colour so produced.

The care and maintenance of plant for manufacturing the substances and for their sulphonation or conversion into finished colour.

The washing of casks contaminated with $\alpha$ naphthylamine, $\beta$-naphthylamine, and benzidine, and the weighing out of these materials.
The purification of $\beta$-naphthylamine and benzidine, the total time involved being less than 100 working hours, has apparently caused one case, and longer exposure as a supervising chemist another case.

It is necessary to consider the characteristics of occupational tumours of the bladder in order that the course of events may be understood. The methods of determining the factors at work are technical, and the factors largely interdependent. It is therefore difficult to develop the argument in a strictly logical sequence; some of the characteristics will be used before their meaning is discussed and, in general, the technical process of arriving at the characteristics will be dealt with in the statistical appendix. In these statistical procedures, unless otherwise stated, only the cases derived from Group I $\alpha$ - or $\beta$-naphthylamine, benzidine, or mixed contacts will be used. This is to avoid using a heterogeneous group, and to provide a standard measure of risk. The number of cases in the other two groups is too small to allow statistical conclusions to be drawn about the characteristics of induced tumours, but the cases can be used for comparison with Group I (see Table 9).

The first characteristics to be considered will be

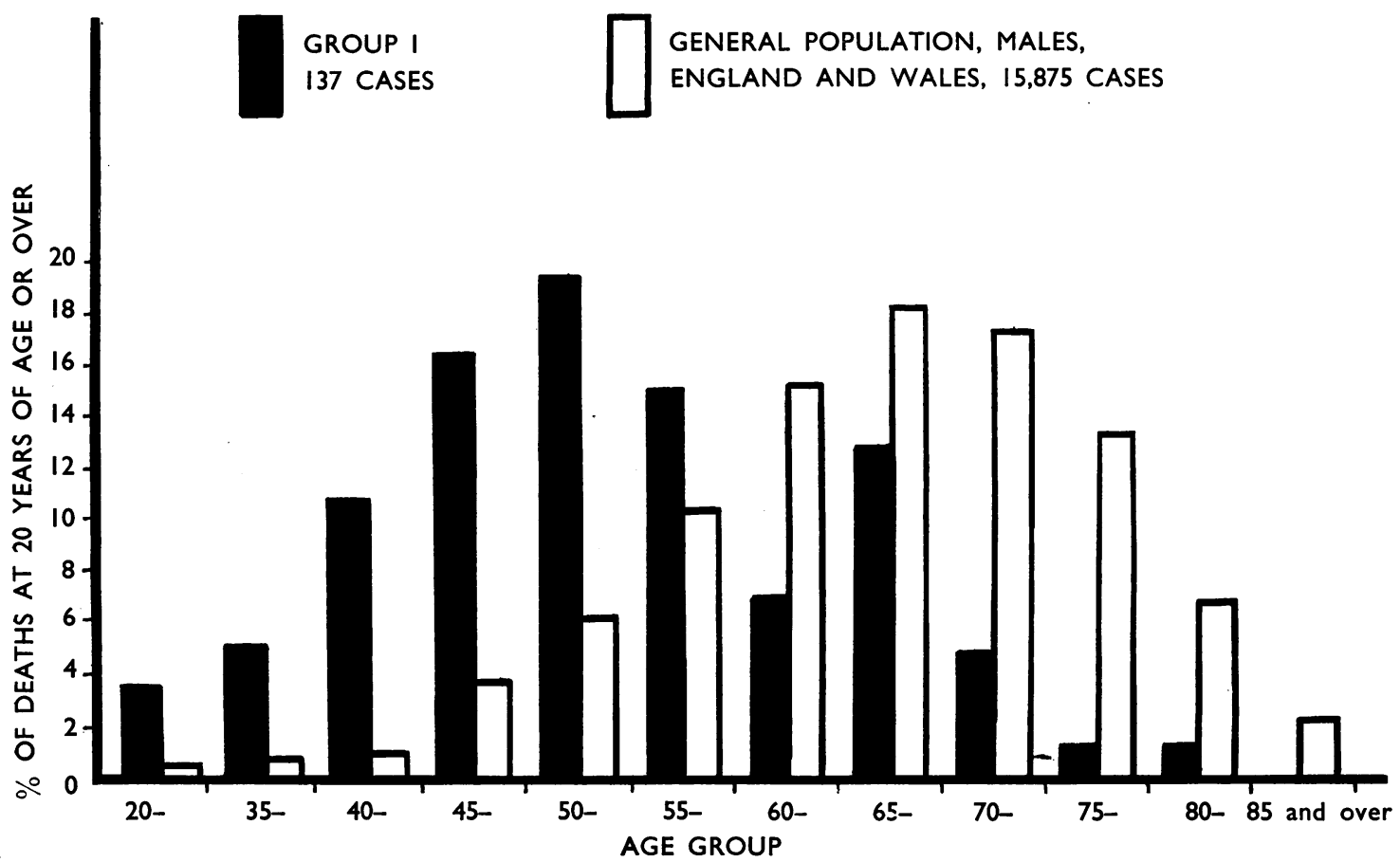

Fig. 1.-The age at $d$ :ath. 
the age at which the tumours appear, and the length of time which elapses between the first exposure to risk and the recognition of the tumour. These will be termed the age of onset and the induction period respectively. The age at which naturally occurring tumours appear in the general population is required, but, since there is not enough information available to form a reliable estimate for the whole country, this cannot be determined at present, though such an estimate can be made for Birmingham and district (see Statistical Appendix). However, the age at death for all males in England and Wales whose death certificates mention bladder tumour can be determined for any year from 1921 to 1949, and therefore these figures are compared with the age at death of the 137 cases from Group I whose death certificates mention tumour of the bladder. (These cases are not all derived from the nominal roll.) Fig. 1 shows the percentage at each age group of the total number of deaths in each of these two groups for persons over 20 years of age.

It is shown that these 137 cases from firms in Group I died of bladder tumour at an earlier age than would be expected from the data relating to England and Wales, the most frequent age of death in the occupational group (50-55 years) being 15 years earlier than the most frequent age $(65-70$ years) in the general population. Thus the occupational hazard produces not only an increased number of deaths from bladder tumour, but also death from this complaint at an earlier age.

It now becomes pertinent to enquire whether this earlier age at death from bladder tumour is due first to a more limited survival time from the outset of the disorder; secondly to a selectively greater susceptibility to the disorder in younger men; and thirdly to a relationship between the age at exposure to risk and the age at onset, or whether some combination of these factors is at work. The first of these hypotheses cannot be tested directly by comparison with survival times since proper hospital records have not been available for a long enough period. An approximate answer can be given by comparing the age at onset of the group of chemical workers with the age at onset of a group of 750 male cases of bladder tumour reported from the Birmingham hospitals between 1936 and 1951. This comparison is given in Fig. 2, which shows clearly that the movement to lower age groups is still very marked, the most frequent age of onset of the chemical workers in firms in Group I (40-50 years) being 20 years earlier than the most frequent age of onset for Birmingham males (60-70 years). It is thus apparent that the earlier age at death is not due to a more limited survival time.

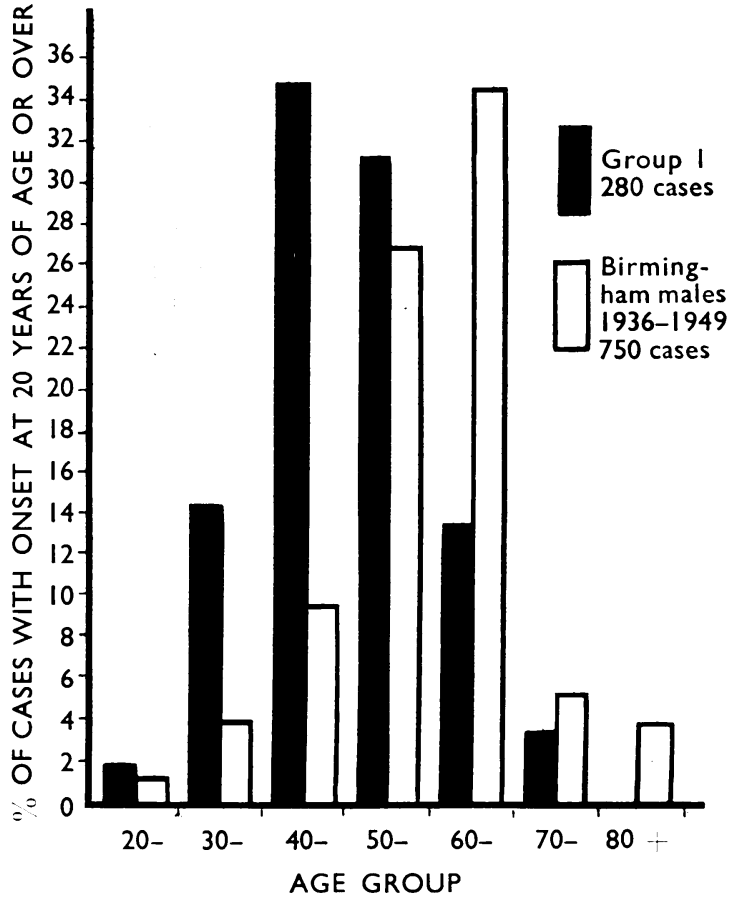

FIG. 2.-The age at onset. In a further seven cases, ages at onset were not known.

The second hypothesis was tested by calculating the number of cases that would be expected from persons entering any of the hazardous occupations (exposure to benzidine, $\alpha$-naphthylamine, or $\beta$ naphthylamine) in the different age groups at the time of entry, on the assumption that this played no part in the production of tumours, and comparing the expected number with the number actually found, and these figures are shown in Table 4. It is shown that an older age of entry into risk increases somewhat the chance of developing a tumour, and therefore the earlier age of onset is not due to an increased susceptibility of younger persons.

The third hypothesis was tested by plotting the average age of onset against the age at entry in age groups. The result of this calculation is shown in Fig. 3. This shows that the age of onset is dependent almost entirely upon the age of entry, the induction period being nearly constant. The lack of complete agreement shown can be accounted for by the increasing loss of men who might otherwise develop bladder tumours by death from other causes in the older age groups. For all practical purposes, the younger a man is when he enters risk, the younger will he be when he gets a tumour, and the most common time to develop a tumour will be between 
TABLE 4

NO. OF EXPECTED CASES IF AGE AT ENTRY HAD NO EFFECT ON INCIDENCE AND NO. FOUND

\begin{tabular}{|c|c|c|}
\hline $\begin{array}{l}\text { Age at } \\
\text { Entry }\end{array}$ & $\begin{array}{l}\text { Expected No. of Cases Allowing for } \\
\text { Death from All Causes at } 1931 \text { Rates }\end{array}$ & $\begin{array}{l}\text { Tumours } \\
\text { Found }\end{array}$ \\
\hline Under 20 & 22 & 13 \\
\hline $20-$ & 109 & 90 \\
\hline $30-$ & 74 & 75 \\
\hline $40-$ & 29 & 52 \\
\hline $50-$ & 5 & 8 \\
\hline 60 and over & 0 & 0 \\
\hline TOTAL & 239 & 238 \\
\hline \multirow[t]{2}{*}{ Unknown } & - & 5 \\
\hline & Total & 243 \\
\hline & $\begin{array}{l}x^{2}=27.6 \\
\mathbf{n}=4 \\
\mathbf{P}<.001\end{array}$ & \\
\hline
\end{tabular}

15 and 20 years after starting work in the dangerous environment.

The apparent constancy of the average time from first exposure to development of a tumour for each age group of entry into risk suggested that the induction time should be studied further. Accordingly, the induction times of all cases in each exposure class were examined, and the average time and the scatter around it determined. The values are benzidine exposures 16 (S.D. 5) years, $\alpha$-naphthylamine exposures 22 (S.D. 6) years, $\beta$-naphthylamine exposures 16 (S.D. 6) years, mixed exposures 18 (S.D. 7) years, and the mean for the combined series 18 (S.D. 7) years. The mean induction time for benzidine and $\beta$-naphthylamine is the same, but there is a real difference between this time and that for $\alpha$-naphthylamine, where the mean time is six years $(37.5 \%)$ longer. The spread of the induction times for all the cases pooled together is shown in Fig. 4. (The superimposed normal curve is discussed in the appendix.) This shows that while the most frequent induction time is between 15 and 20 years from exposure, tumours can develop within five years or after 45 years from the first entry into risk. This is of practical importance because it means that it is possible for a case of bladder tumour to be of occupational origin even if the induction time is very short or very long.

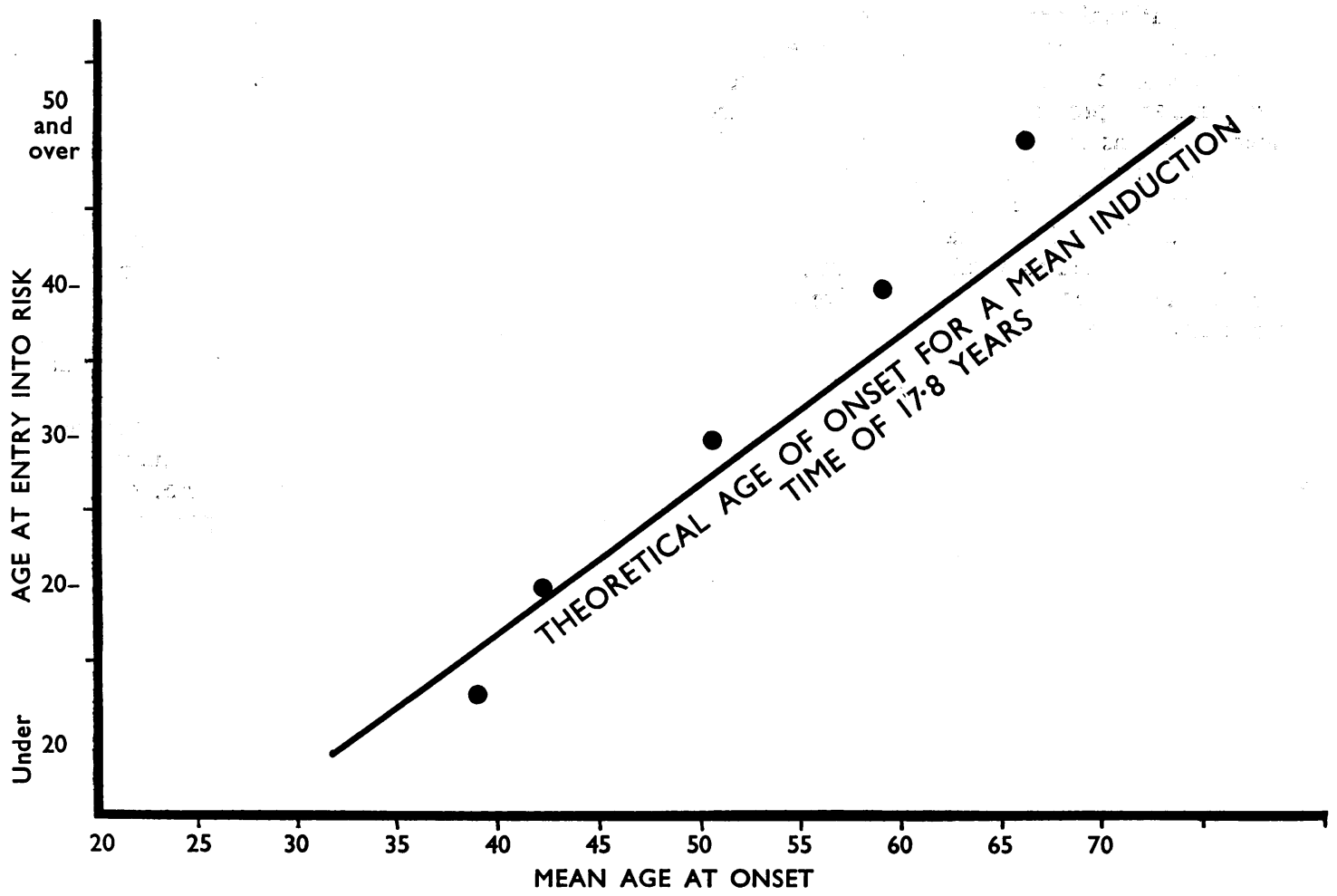

Fig. 3.-Age at entry and age at onset. 


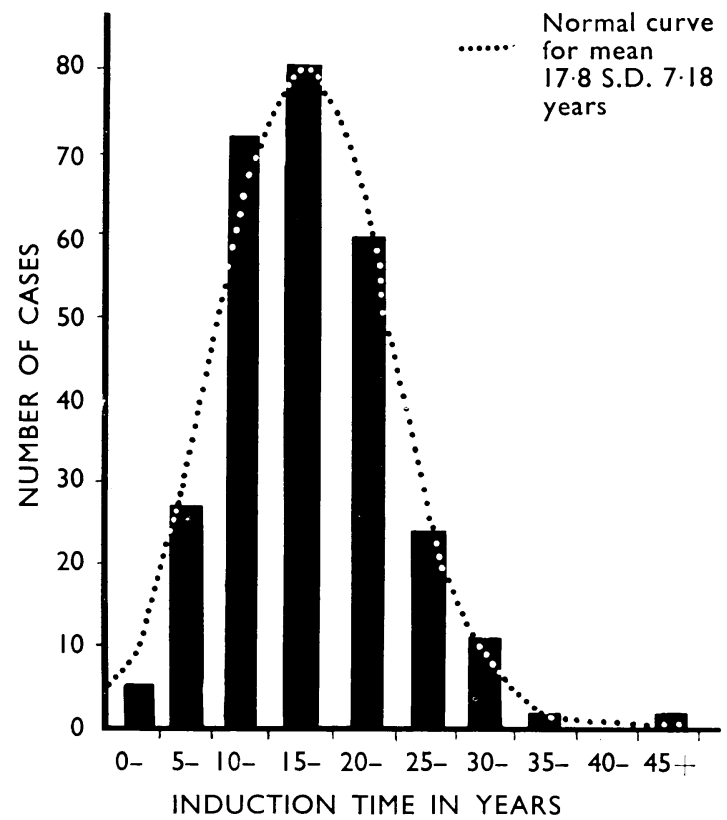

FIG. 4.-The distribution of induction times in Group I (281 cases). In a further six cases induction times were not known.

It is necessary to see whether the variation in induction time is an expression of the dose of the noxious material encountered. If it is such an expression, then men receiving a smaller dose should tend to get tumours after a longer interval, and men receiving a larger dose after a shorter interval. No direct measure of the dosage received is available but it is reasonable to suppose that the length of exposure will be some sort of indication of the amount of the substance encountered. However, there will obviously be a number of patients who have worked in the hazardous environment until the onset of the disorder, and here of course the length of exposure and the induction time will be identical. There will also be a number of men where the induction time exceeds the exposure time. In all, there are 281 cases in Group I where both the exposure and induction times are known. These 281 cases are shown in Table 5, subdivided into groups according to the length of the two times. The number of cases in each group that would be expected if the exposure time did not affect the induction time has been calculated and is also shown. The method of calculation is discussed in the appendix. There is no trend to suggest that there is an association between short exposure times and long induction times, or vice versa, and the deviations from the expectation are no more than could be reasonably attributed to chance variations of sampling.

Another more approximate measure of the severity of exposure might be the supposition that manufacturers of a substance will be more heavily exposed than users. If this is so and if the severity of exposure did affect the induction time, then the manufacturers should show a preponderance of shorter induction times and a shorter mean induction time. Table 6 shows the number of cases in each group of induction times that would be expected in users if severity of exposure had no effect, and if there were equal numbers of users and manufacturers, and also the number actually found. The observed differences are no greater than could easily occur by chance. The mean induction time of the manufacturing group ( $17 \cdot 7$ years) does not differ from that of the using group (18.3 years) by more than might occur by chance. Thus it may be concluded that the severity of exposure, as judged by these methods, has no effect on the induction time of the disorder. The mean induction time in Groups II and III combined, where, as will be shown later, the risk is much smaller, does not differ materially from these figures. It would therefore appear that this mean induction time is characteristic of the particular substance concerned, and not dependent on the severity of the exposure. The fact that, within the terms chosen for the analysis, these factors are independent makes it possible to use the observed distribution of the induction times as a basis for calculating the expected appearance of tumours, and the underlying principle of the subsequent analysis rests upon this independence.

Another implication of the independence is that the difference of the mean induction times for $x$ naphthylamine and $\beta$-naphthylamine suggests that the $\beta$-naphthylamine content of the $\alpha$-isomer may not be the sole active agent, unless $x$-naphthylamine exerts a delaying action on the rate of development of 3 -naphthylamine tumours.

\section{Severity of the Incidence in Population at Risk at Different Times}

It is necessary to consider how the incidence in the population at risk varies at different times, and what factors influence this variation. Accordingly the nominal roll for Group I was divided into groups who started work in the hazardous occupations in the years 1910-1919, 1920-1924, 1925-1929, and so on in five-year groups to 1945-1949. Each group was further subdivided into the length of time which the man remained in the occupation. This subdivision was carried out for each class of benzidine 
TABLE 5

NO. OF CASES FOUND AND EXPECTED IN EACH EXPOSURE TIME GROUP IF LENGTH OF EXPOSURE DOES NOT INFLUENCE INDUCTION TIME : GROUP I

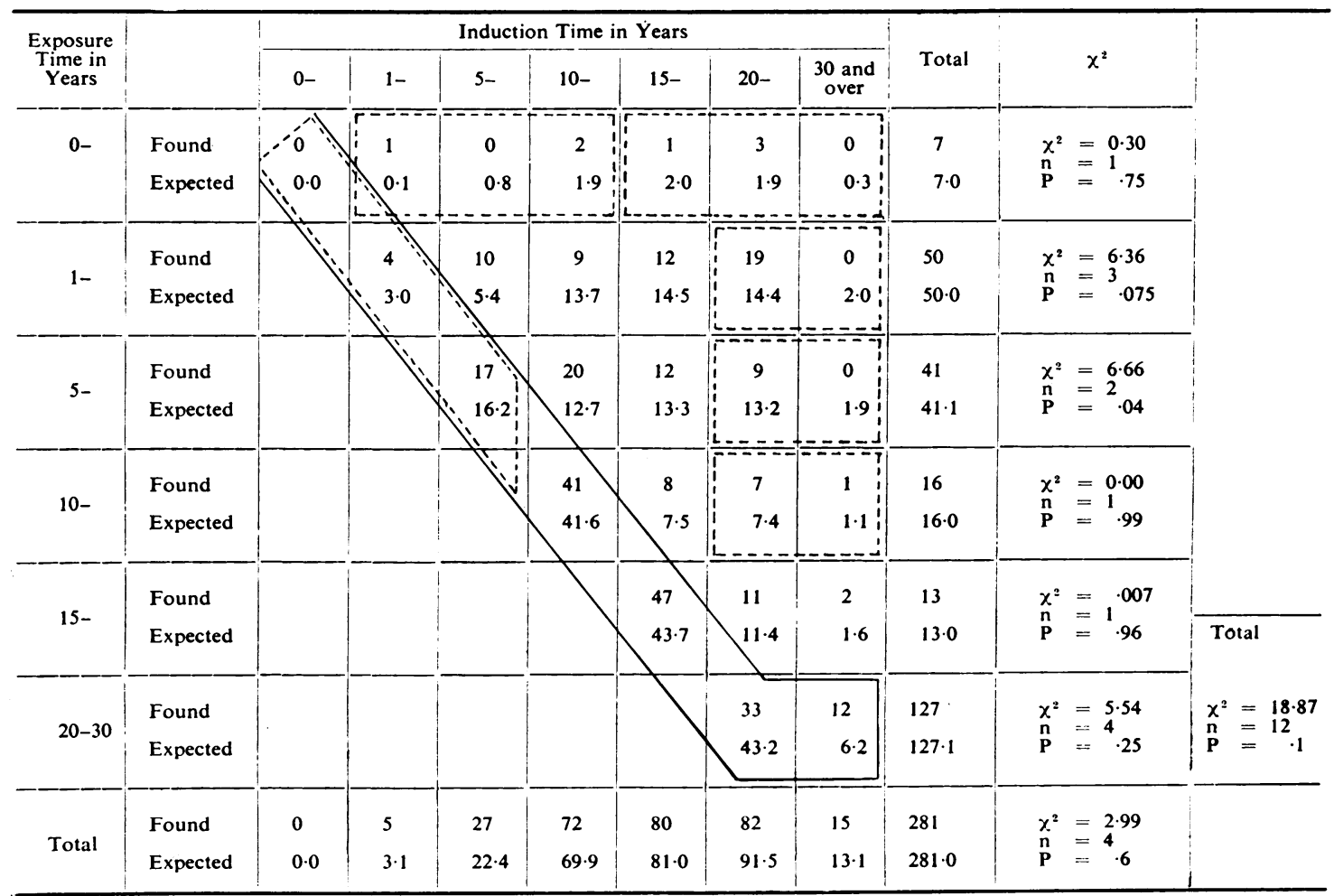

The dotted lines indicate groups combined in carrying out $\chi^{2}$ test which is discussed in the statistical appendix.

TABLE 6

THE EFFECT OF MANUFACTURING OR USE ON THE INDUCTION TIME

\begin{tabular}{|c|c|c|c|c|c|c|c|}
\hline Induction Time (years) & Under 5 & $5-$ & $10-$ & $15-$ & $20-$ & Over 30 & Mean and S.D. \\
\hline $\begin{array}{c}\text { Cases found in the manufacturing } \\
\text { group }\end{array}$ & 2 & 18 & 38 & 47 & 35 & 9 & $18 \cdot 18=8 \cdot 5$ \\
\hline $\begin{array}{l}\text { Cases in user group calculated for } \\
\text { a group of equal size } \ldots\end{array}$ & 3 & 14 & 35 & 43 & 43 & 11 & $17.63 \pm 7.3$ \\
\hline $\begin{array}{c}\text { Difference of Distribution } \\
\chi^{2}=4.09 \\
n=4 \\
P=4\end{array}$ & $\begin{array}{l}\text { The dotte } \\
\text { carrying }\end{array}$ & ind $x^{2}$ & oups & tog & & \multicolumn{2}{|c|}{$\begin{array}{c}\text { Difference of means } \\
\chi^{2}=0.55 \\
t=0.72 \\
P=.4\end{array}$} \\
\hline
\end{tabular}

exposure, $\alpha$-naphthylamine exposure, $\beta$-naphthylamine exposure, and mixed exposure, and also for all these exposures pooled together. The cases derived from the nominal roll were arranged in similar subdivisions, so that the percentage incidence arising from each subdivision could be calculated. Fig. 5 shows the percentage of the population in each group according to the date of starting developing bladder tumour, irrespective of the date of tumour development, age at entry, or length of service. This figure is calculated from the pooled classes. (The superimposed cumulative normal curve is discussed in the appendix.) It is seen that as the date of starting gets earlier the percentage of the population affected gets larger, until a steady level of just under $20 \%$ of the original population being 


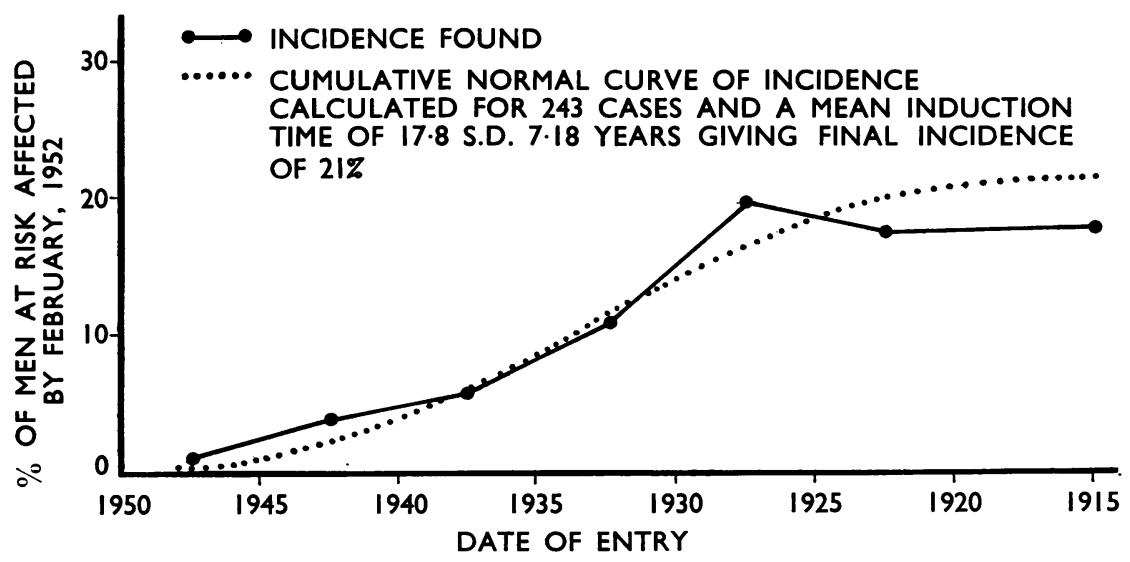

FIG. 5.-The crude incidence at different times. Pooled exposures in 243 cases of Group I. effective exposure, which is defined as the length of time of exposure necessary for the particular class of exposure to produce the average risk for that class of exposure.

The number of cases of tumour occurring in each grouped length of exposure class, using the groupings shown, was found, and the figures expressed as a percentage of those expected if the length of exposure had no effect, i.e., the affected is reached. It becomes necessary to find out which factors other than the induction times are responsible for the shape of this graph. It might be that in earlier times exposures were greater and protective methods less good ; it might be that men were exposed for longer periods in earlier years, or it might be that some combination of these factors is at work. It is also necessary to see whether each of the three substances produces a similar or dissimilar severity of incidence. Fig. 6 shows a graph for each of the four classes of exposure that were combined in Fig. 5. Although these graphs show obvious dissimilarity, a consideration of this must be postponed until the effect of the length of exposure has been evaluated.

There is already a suggestion that the severity of exposure affects the number of cases that will be found, since relatively fewer cases occurred amongst the employees of Group II and III firms. The length of exposure may, as said before, be regarded as some measure of the severity of exposure. The graphs already considered (Figs. 5 and 6) did not take any account of the length of exposure in each date group of entry into work. They may thus be regarded as being calculated from the mean figure for the mean effective exposure is called $100 \%$. The results of these calculations are shown for each class of exposure in Fig. 7. From this it can be seen that the length of exposure has in all classes a profound effect on the number of cases produced, and that the mean effective exposure is reached after a varying exposure time. It is also shown that the risk of developing a tumour increases to a maximum and then decreases for men who have been employed for a long time. This strongly suggests that for a given level of risk, where risk is the sum total of all factors causing bladder tumour, there are members of the population being considered who are susceptible to the disorder and members who are not. Altering the

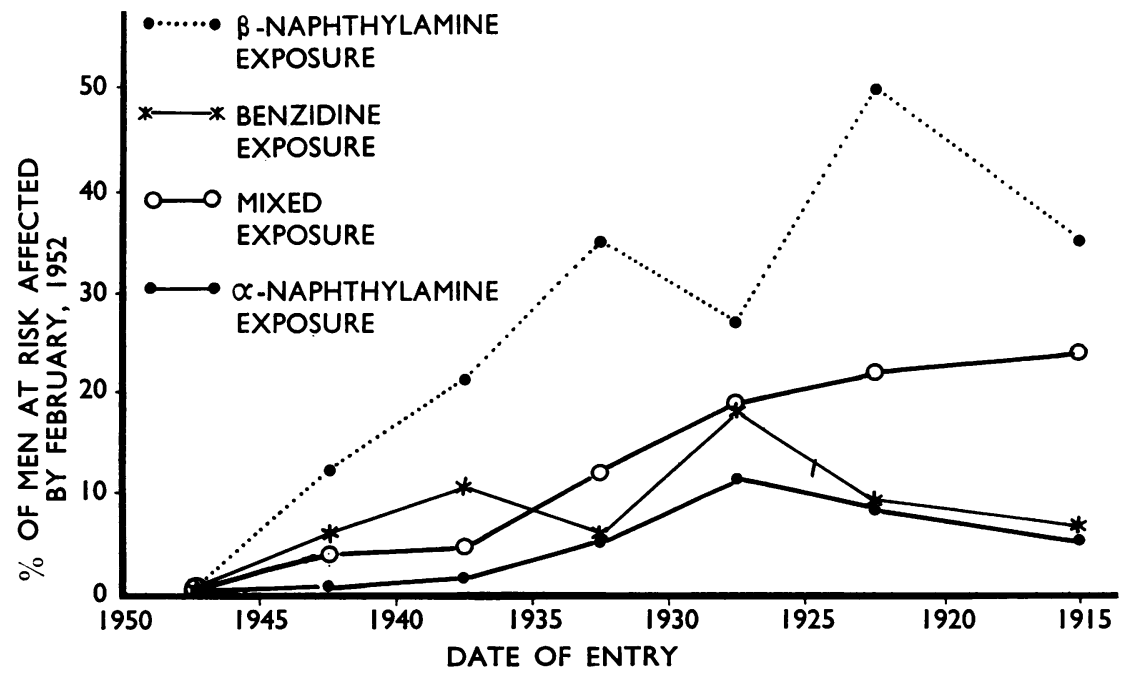

FIG. 6.-The crude incidence at different times by exposure class. 


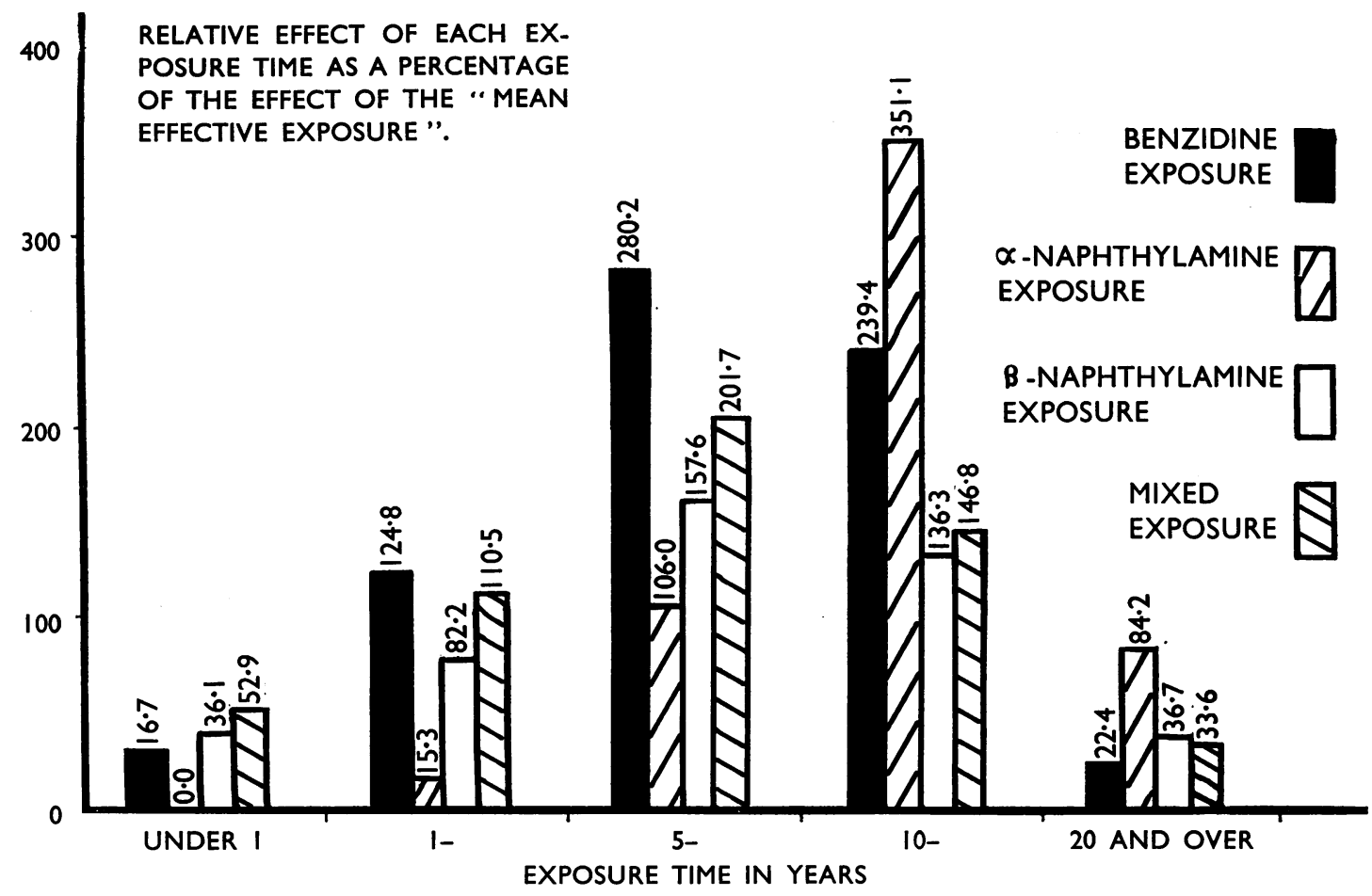

Fig. 7.-The effect of exposure time by exposure class.

level of risk will alter the relative proportions of these two groups, and it is probable that a high enough level would produce a $100 \%$ affected group and a low enough level an almost unaffected group. The fall in the severity of incidence after long exposure times means that most of the persons who will be affected have already contracted tumours, and so have been removed from the figures available for calculation. This apparent immunity is a statistical concept. It may be due to the fact that the population at risk consists of some who really have little or no contact with the substance concerned ; that some of the men acquire a "knowhow", either conscious or unconscious, that enables them to avoid risk ; that inherently in themselves they possess a resistance ; or that more than one of these factors is at work.

Whatever the actual explanation of the graph, from a practical aspect it means that exposures of less than one year to benzidine, $\beta$-naphthylamine, and mixed exposures have already produced sufficient effect to make it impracticable to attempt to obviate the risk solely by reducing the employment time. $\alpha$-Naphthylamine appears to require a longer exposure for equivalent effect, but too much reliance should not be placed on the low incidence found at very short exposures, since the number of cases available for study is very small, and therefore the conclusions tend to be unreliable.

Applying this knowledge of the effect of the exposure time on the number of tumours produced, it becomes possible to represent graphically the tumour incidence that would occur at different times if all the exposures had been of the same length, namely of the mean effective exposure. In this way the number of tumours that would have occurred in the nominal roll for each class of substance had the men been exposed for the mean effective exposure to a standard substance that has a mean potency can be calculated, and is shown in Table 7. (A standard substance is defined as a hypothetical substance whose activity in the production of bladder tumours represents the average activity of the substances actually met with by the men at standard risk, and a mean potency as the average measure of the power of the standard substance, with exposure for the mean effective exposure time to produce tumours in a population.at risk of known size observed from the date of entry into risk after 1910 until 1952.) A comparison of these numbers 
TABLE 7

EFFECT OF THE EXPOSURE CLASS

\begin{tabular}{|c|c|c|c|c|}
\hline$\underset{\text { Class }}{\text { Exposure }}$ & Benzidine & $\alpha-$ Naphthyl- $_{\text {amine }}$ & $-\underset{\text { amine }}{\beta-N a p h t h y l-\mid}$ & $\begin{array}{c}\text { Mixed } \\
\text { Exposures }\end{array}$ \\
\hline $\begin{array}{c}\text { No. of cases } \\
\text { expected }\end{array}$ & 47.0 & 46.9 & $25 \cdot 5$ & $124 \cdot 0$ \\
\hline $\begin{array}{c}\text { No. of cases } \\
\text { found }\end{array}$ & 34 & 19 & 55 & 135 \\
\hline$\overline{\text { Relative potency }}$ & $72 \%$ & $41 \%$ & $216 \%$ & $109 \%$ \\
\hline $\begin{array}{l}\text { Ultimate rela- } \\
\text { tive potency }\end{array}$ & $68 \%$ & $58 \%$ & $185 \%$ & $127 \%$ \\
\hline
\end{tabular}

with the numbers actually found gives a measure of the relative potency of each individual compound expressed as a percentage of the mean potency; where the relative potency is defined as the average measure of the power, expressed as a percentage of the mean potency, of a specified class of exposure, with exposure for the mean effective exposure time for that class of exposure, to produce tumours in a population at risk of known size, observed from the date of entry into risk after 1910 until 1952.

Statistical tests show that this relationship between the substances held true generally over the period between 1915 and 1950. Thus it can be said that, under the exposure conditions obtaining in the Group I firms between these dates, $\beta$-naphthylamine has been the most potent cause of bladder tumour, followed by mixed exposures, then by benzidine, with $\alpha$-naphthylamine the least potent of these substances. $\beta$-Naphthylamine has been about five times as potent as $\alpha$-naphthylamine, and three times as potent as benzidine.

However, the differing mean induction times for the different substances suggest that this may underestimate the relative potency of the substances with the longer induction times. Therefore a measure, called the " ultimate relative potency", has been calculated and is necessary to express what these relationships would be when all the expected cases at the mean risk have developed, on the assumption that men die of all causes at 1931 rates. This measure is defined as the measure of the power, expressed as a percentage of the ultimate mean potency, of a specified class of exposure, with exposure for the mean effective time for that class of exposure, to produce tumours of the bladder in a population at risk of known size observed until all have died, on the assumption that death from all causes acts at the 1931 rate for males in England and Wales. These ultimate relative potencies are also shown in Table 7. It can now be seen that the relative potencies of $\alpha$-naphthylamine and mixed exposures have been underestimated and that of $\beta$-naphthylamine overestimated by the relative potency figures.

\section{Effect of Changing Conditions and Altered Techniques on the Incidence at Different Times}

The only factors so far investigated that affect the final incidence of tumours are the type of substance encountered and the length of exposure. Fig. 8 shows what the result would be if all the men had been exposed to each exposure class for the mean effective exposure time, and, by the use of the potency factors, if all the men were working at the mean potency. This removes chance influences due to the number of men working on a particular substance at a given time, and to different movements of labour that may take place at different times. The incidence in the population at risk entering the relevant occupations at different dates increases, slowly at first, then more sharply, and then again slowly, with the passage of time since starting work. The highest figure reached is about $24 \%$, and a time will come when the final incidence is reached since deaths from all causes will leave no more men in the original population to be affected.

The data that have been collected about the induction times make it possible to calculate a

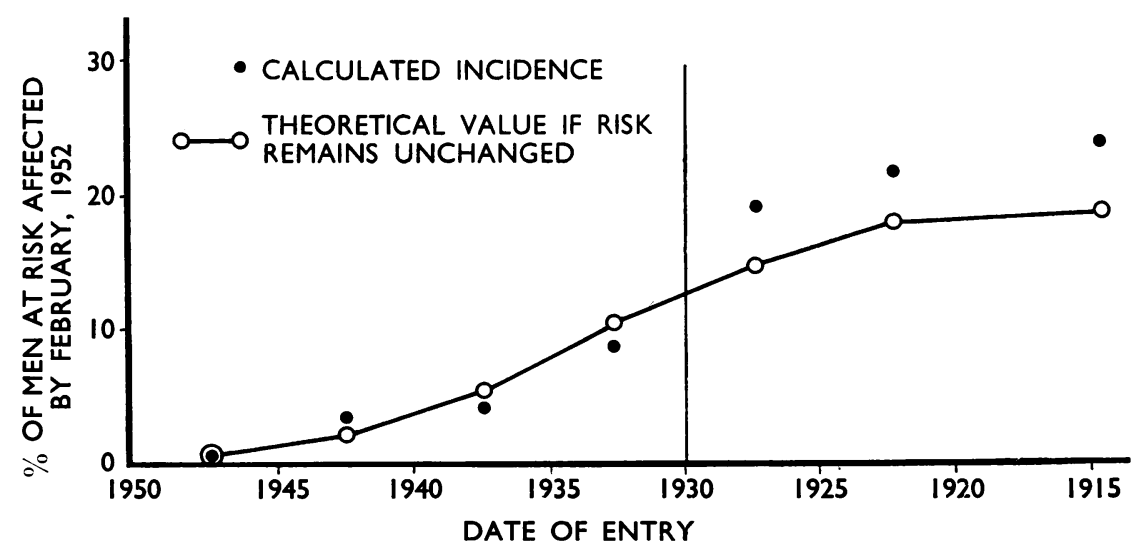

FIG. 8.-The incidence at different times calculated from the mean effective exposure time and the mean potency in 243 cases of Group I. 


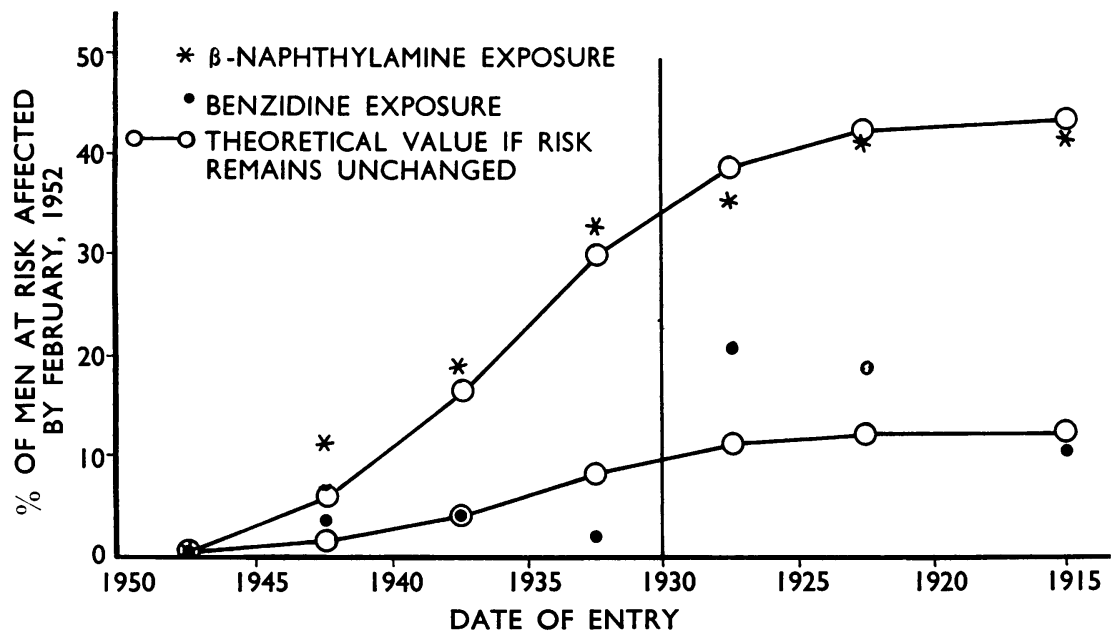

FIG. 9.-The incidence at different times by exposure class. the later period. Statistical tests show that this difference of estimate is slightly more than could reasonably be expected to occur by chance. The analysis of the figures reveals that the mean post-1930 risk is about $66 \%$ of the mean pre1930 risk, but it is safer to limit this conclusion more generally to stating that the risk is reduced just significantly. It is not possible yet to say that this improvement is progressive, since cases which may be expected to occur in men who graph of the way in which the incidence figures would behave if it is assumed that the "dangervalue" of exposure for a given time is constant between 1915 and 1950 ; in other words, that any alterations of plant and process have been without effect, and if it is further assumed that deaths from all causes affect the men at the rates found in the male population of England and Wales for 1931, this date being the nearest to the centre of the period being considered for which such information is available. Fig. 8 shows this curve as well as the values that were actually found.

Alterations of plant and technique which might be expected to have affected the risk were made first in about 1935, and developed progressively with additional impetus after 1945. Since it has already been shown that the full effect of exposure is not experienced until after an exposure time of more than five years, the men entering between 1930 and 1935 may be expected to benefit to some extent by any reduction of risk that has taken place between 1935 and 1940. If, therefore, this graph is considered as consisting of two groups of men, those entering before 1930 and those entering after 1930, it can be seen that the theoretical line underestimates the risk in the earlier period, and overestimates the risk in entered after 1945 would be very few, and the results of improvements inaugurated then are not yet assessable.

How Individual Classes of Exposure Follow the Type of Theoretical Curve in Figs. 9 and 10

Figs. 9 and 10 show the theoretical expected incidence for the four exposure classes calculated on the assumptions that the risk remained constant throughout the whole period, and that the death rate from all causes was at the 1931 figure. The incidences actually found are also shown. An analysis of these curves shows that the mean post1930 risks for benzidine and for mixed exposures are reduced by more than could be expected from chance sampling variations (to $39 \%$ and to $67 \%$ of the pre-1930 risk respectively) and also that the mean post-1930 risks for $\alpha$-naphthylamine and $\beta$-naphthylamine have risen, being $118 \%$ of the 
pre-1930 risk in each case, but this difference does not exceed what might be attributed to chance sampling variations. The slight total diminution of risk shown in Fig. 8 is derived from the benzidine and mixed exposures classes, though any quantitative estimate of the change should also be treated with reserve.

The theoretical graphs for the mean risk over the whole period conform reasonably closely to the curve that has been found for the exposure classes $\alpha$-naphthylamine, $\beta$-naphthylamine, and (apart from the diminution of risk since 1930 already noted) mixed exposures. In the case of benzidine the scatter of the observed values around the theoretical graph will be seen to be greater. Detailed histories of changes in industrial technique are not available for all firms or for all of the exposure classes, but $68 \%$ of the benzidine cases are contributed by one firm, and were engaged in the manufacture of this substance. Scott (1952) has given a historical summary of the manufacture of benzidine by that concern. It is of interest to attempt to correlate this history with the graph of the tumour incidence for the exposure class benzidine, and this is done in Fig. 11. In drawing the comparison, the assumption has again been made that a change of process will affect men who entered in the five-year period before the change was made, but not men who entered more than five years previously. The figures given are the incidences found expressed as percentages of the incidences that would be expected if the risk had been constant throughout the period. The last three groups are combined because a comparison of cases with very low expectation figures is not precise, since the actual cases can only be whole numbers. There is a suggestion that the isolation of the base, as opposed to the conversion of the sulphate to the base, increases the risk. Such a deduction should be treated with reserve, since this type of analysis can be fallacious. There is not enough evidence to make any comment about the isolation of the hydrochloride.

HISTORY OF BENZIDINE MANUFACTURE (SCOTT, 1952)

BENZIDINE PROCESS : ZINC REDUCTION.

PRODUCT ISOLATED AS :-

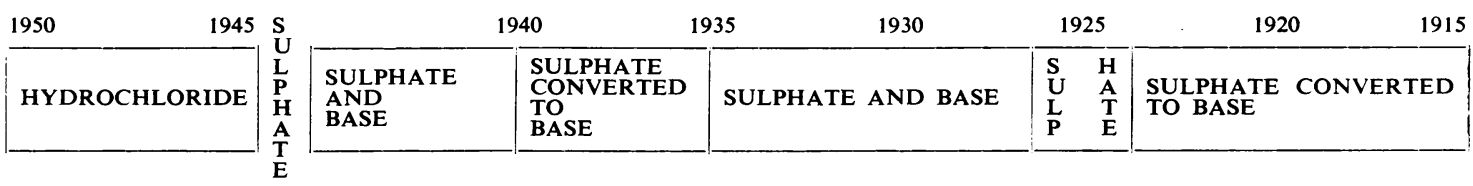

HISTORY AS IT WILL AFFECT THE INCIDENCE IN EACH DATE-OF-ENTRY GROUP :-

\begin{tabular}{|c|c|c|c|c|c|c|}
\hline 1950 & 45 & 40 & & 30 & 25 & 1915 \\
\hline HYDROCHLORIDE & $\begin{array}{l}\text { SULPHATE } \\
\text { AND } \\
\text { BASE } \\
\text { HYDROCHLORIDE }\end{array}$ & $\begin{array}{l}\text { SULPHATE } \\
\text { CONVERTED } \\
\text { TO BASE } \\
\text { SULPHATE } \\
\text { AND BASE }\end{array}$ & $\begin{array}{l}\text { SULPHATE } \\
\text { CONVERTED } \\
\text { TO BASE } \\
\text { SULPHATE } \\
\text { AND BASE }\end{array}$ & $\begin{array}{l}\text { SULPHATE } \\
\text { AND } \\
\text { BASE }\end{array}$ & $\begin{array}{l}\text { SULPHATE } \\
\text { CONVERTED } \\
\text { TO BASE } \\
\text { SULPHATE } \\
\text { AND BASE }\end{array}$ & $\begin{array}{l}\text { SULPHATE } \\
\text { CONVERTED } \\
\text { TO BASE }\end{array}$ \\
\hline
\end{tabular}

CHANGES INTRODUCED THAT WILL AFFECT EACH DATE-OF-ENTRY GROUP :-

\begin{tabular}{|c|c|c|c|c|c|c|}
\hline 1950 & 45 & 40 & 35 & 30 & 25 & 1915 \\
\hline & $\begin{array}{l}\text { ISOLATION OF } \\
\text { HYDROCHLORIDE }\end{array}$ & $\begin{array}{l}\text { DISUSE OF } \\
\text { SULPHATE } \\
\text { CONVERTED } \\
\text { TO BASE }\end{array}$ & $\begin{array}{l}\text { RE-USE OF } \\
\text { SULPHATE } \\
\text { CONVERTED } \\
\text { TO BASE }\end{array}$ & $\begin{array}{l}\text { DISUSE OF } \\
\text { SULPHATE } \\
\text { CONVERTED } \\
\text { TO BASE }\end{array}$ & $\begin{array}{l}\text { ISOLATION OF } \\
\text { BASE }\end{array}$ & \\
\hline
\end{tabular}

NO. OF CASES FOUND IN EACH PERIOD AS \% OF NO. OF CASES EXPECTED IF RISK HAD REMAINED CONSTANT AT THE MEAN RISK :-

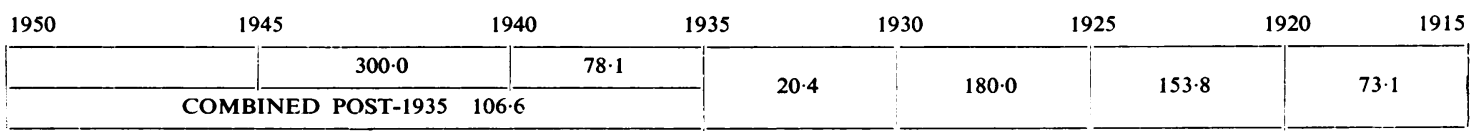

DATE-OF-ENTRY GROUP

Fig. 11.-The possible effect of the history of benzidine manufacture on the severity of incidence at different times. 
Total Expected Number of Cases from the Nominal Roll in Group I Only

The type of graph shown to fit the observed incidences of bladder tumour in the various classes (see Figs. 9 and 10) makes it possible to calculate the numbers of cases that will be expected to occur on the assumptions that the death rate from other causes remains at the 1931 level, that none of the men on the nominal roll received further exposure after the end of 1950, and that the cases occur at the mean risk for the pre-and post-1930 periods for the men who entered at these times. By assuming in this way that conditions have remained static, it is practicable to obtain an indication of the number of cases which may still be expected in the population here considered, but since conditions have not in fact remained static the figures obtained are only a rough measure of the problems to be faced. They are shown in Table 8.

TABLE 8

NUMBER OF CASES EXPECTED FROM GROUP I

\begin{tabular}{lrr|c|c|c}
\hline Exposure Class & & $\begin{array}{c}\text { Total No. } \\
\text { of Cases } \\
\text { Expected }\end{array}$ & $\begin{array}{c}\text { No. of Cases } \\
\text { Already } \\
\text { Found }\end{array}$ & $\begin{array}{c}\text { Further } \\
\text { Cases to be } \\
\text { Expected }\end{array}$ \\
\hline Benzidine &. &. & 58 & 34 & 24 \\
\hline$\alpha$-Naphthylamine &. & 70 & 19 & 51 \\
\hline$\beta$-Naphthylamine &.. & 93 & 55 & 38 \\
\hline Mixed exposures &.. & 265 & 135 & 130 \\
\hline Total.. &.. &.. & 486 & 243 & 243 \\
\hline
\end{tabular}

Another Measure of the Severities of the Risks in Each Exposure Class and in the General Population

In considering the risk involved in exposure to the three substances benzidine, $\alpha$-naphthylamine, and $\beta$-naphthylamine, only patients who were dead, and where death certificates mentioning bladder tumour had been issued, could be used in determining the risk. It is now possible to devise another measure which will utilize the information from all the cases on the Group I nominal roll. This measure is the final incidence, after allowing for deaths from all causes at the 1931 rate, that will be reached for each class of exposure, and the comparison is with the final incidence for the general population. This can be calculated from the final incidence of death certification with mention of bladder tumour, together with the percentage certification with mention of bladder tumour of the cases in the hospital survey. The final incidence of death certification with mention of bladder tumour used is the figure for $1931(0.56 \%)$ for men entering at age 34 , this being the average age of entry for the period investigated. From this we find that the final incidence of cases of bladder tumour in the male general population is $0 \cdot 70 \%$, while the final incidences for benzidine, $\alpha$-naphthylamine, $\beta$-naphthylamine, and mixed exposures in Group I are $13 \%, 11 \%$, $43 \%$, and $23 \%$ respectively.

This confirms the previous test and further provides a rough estimate of the severity of the hazard, the benzidine hazard being 19 times, the $\alpha$-naphthylamine hazard 16 times, the $\beta$-naphthylamine 61 times, and the hazard from mixed exposures 33 times as great as that in the general population. In addition to the increased number of cases found, the occupational cases occur at a much earlier age than the non-occupational ones.

\section{The Severity of the Risk in Groups II and III Firms}

From the foregoing it is possible to calculate the number of cases that would have been expected from the nominal rolls of Group II and Group III firms if the risk were the same as in Group I, and to compare this expectation with the number of cases found whose names appear on the nominal rolls as having had contact with benzidine, $\alpha$-naphthylamine, or $\beta$-naphthylamine. These figures are shown in Table 9. Both Group II and Group III firms have a

TABle 9

SEVERITY OF RISK IN GROUPS II AND III FIRMS COMPARED WITH RISK IN GROUP I FIRMS

\begin{tabular}{|c|c|c|c|c|c|c|}
\hline \multicolumn{4}{|c|}{$\begin{array}{l}\text { Group under } \\
\text { Consideration }\end{array}$} & \multirow{2}{*}{$\begin{array}{c}\begin{array}{c}\text { No. of } \\
\text { Cases } \\
\text { Expected }\end{array} \\
48 \cdot 7\end{array}$} & \multirow{2}{*}{$\begin{array}{c}\begin{array}{c}\text { No. of } \\
\text { Cases } \\
\text { Found }\end{array} \\
7\end{array}$} & \multirow{2}{*}{$\begin{array}{c}\begin{array}{c}\text { Potency of } \\
\text { Risk as \% of } \\
\text { Group I Risk }\end{array} \\
14.4\end{array}$} \\
\hline Group II & . & . & . & & & \\
\hline Group III & . & . & . & $4 \cdot 1$ & 2 & $48 \cdot 7$ \\
\hline \multicolumn{4}{|c|}{ Groups II and III combined } & $52 \cdot 8$ & 9 & $17 \cdot 0$ \\
\hline
\end{tabular}

lesser risk than Group I firms but the risk in Group III firms is not as small as was suggested by the figures derived from death certificates only.

These figures also offer an additional means of testing the hypothesis that the mean induction time is not dependent on the severity of exposure. If it were, the mean induction time for these nine mixed exposure cases in the combined two groups should be longer than for the mixed exposure cases in Group I, and longer than the $\alpha$-naphthylamine cases also. In fact, the mean induction time (21 S.D. 9 years) is not materially different from that of mixed exposure cases in Group I (18.3 S.D. 7. $P=0.25$ ), and is shorter, though not materially so, than that of the $\alpha$-naphthylamine cases from Group I firms (22.5 S.D. 7. $P=0.55)$. 


\section{A Possible Bladder Tumour Hazard in Other Dye- stuffs Processes}

It is now necessary to devote some attention to the cases that were found outside the groups which come into contact with benzidine or the naphthylamines. It has already been shown that aniline does not appear to present a hazard, but that the manufacture of magenta (fuchsine) appears suspicious.

The manufacture of auramine is also under suspicion. Four cases have appeared in auramine workers who have not had contact with either aniline, benzidine, or the naphthylamines, and two cases whose only contact with these substances has been with aniline. Nine other cases had worked on the manufacture of auramine, but also had contact with benzidine, $\alpha$-naphthylamine, or $\beta$-naphthylamine. These nine cases were included in their appropriate exposure classes for the last three substances.

Two of the six auramine cases without such contact are still alive and three have bladder tumour death certificates. While it is impossible to say whether this figure represents an excess of cases over what might be expected if no occupational risk were present, unless the size of the population at risk is known, three death certificates seem highly suspicious when it is remembered that the total expectation from the 4,622 men on the combined nominal roll for aniline, benzidine, and $\alpha$ - and $\beta$ naphthylamine lay between three and five.

Fifteen cases amongst employees of member firms were found who were known not to have had contact with aniline, magenta, auramine, benzidine, or the naphthylamines. Seven of these have bladder tumour death certificates. The processes worked are shown in Table 10. These numbers are too small to allow a comparison between the age of onset and the age at death with those of the general population to be made, but there is no trend observable in this table to suggest that any of the processes listed there are to be suspected, but it is perhaps relevant to note that Henry, Kennaway, and Kennaway (1931) considered that occupations involving exposure to coal-gas, tar, pitch, or soot carried a risk of occupational tumour of the bladder. Two of the cases listed would fall into this category of worker, rather than into occupations proper to the chemical industry.

There are in addition 36 cases amongst past employees of member firms not participating in the scheme where it has been established that the men never had contact with aniline, auramine, benzidine, $\alpha$ - or $\beta$-naphthylamine, and of these, 34 have death
TABLE 10

PROCESSES WORKED BY CASES AMONG EMPLOYEES OF MEMBER FIRMS WITHOUT CONTACT WITH ANILINE, MAGENTA, AURAMINE, BENZIDINE, OR NAPHTHYLAMINES

\begin{tabular}{|c|c|c|c|}
\hline $\begin{array}{l}\text { Age at } \\
\text { Onset }\end{array}$ & $\begin{array}{l}\text { Age at } \\
\text { Death }\end{array}$ & Processes & \begin{tabular}{|c} 
Length of \\
Service
\end{tabular} \\
\hline 61 & $\begin{array}{l}61 . \text { Died } \\
\text { of other } \\
\text { causes }\end{array} \mid$ & Dinitrobenzene and dinitrotoluene & 8 years \\
\hline$?$ & 57 & $\begin{array}{l}\text { Diphenylamine, phenyl-peri-acid, } \\
\text { primuline, sulphur colours, phenyl- } \\
\text { beta-naphthylamine, o-nitro-aniline }\end{array}$ & 25 years \\
\hline 66 & 67 & Nitric acid manufacture & 22 years \\
\hline ? & 59 & Picric acid manufacture & 27 years \\
\hline 46 & 48 & Manufacture of alizarine derivatives & 28 years \\
\hline$?$ & 74 & $\begin{array}{l}\text { Producer gas, handling tar and pitch } \\
\text { Ice plant }\end{array}$ & $\begin{array}{l}5 \text { years } \\
1 \text { year }\end{array}$ \\
\hline 50 & 53 & Manufacture of sulphuric acid & 2 years \\
\hline ? & 48 & Manufacture of dinitrophenol & 5 years \\
\hline 53 & Alive & $\begin{array}{l}\text { Di- } \beta \text {-chloroethyl ether mono- and di- } \\
\text { nitrations }\end{array}$ & 7 years \\
\hline 59 & Alive & Sodium hydrosulphite & 1 year \\
\hline 47 & Alive & $\begin{array}{l}\text { Manufacture of amido-salicylic acid } \\
\text { but worked in the same shed as a } \\
\text { dianisidine plant }\end{array}$ & 5 years \\
\hline 42 & Alive & $\begin{array}{l}\text { Para-, ortho- and chloro-para-tolui- } \\
\text { dine. Next to sodium naphthionate } \\
\text { plant }\end{array}$ & 23 years \\
\hline 60 & Alive & Use of acetic acid and acetic anhydride & 2 years \\
\hline 74 & Alive & $\begin{array}{l}\text { Coal gas worker } \\
\text { Chemical occupation not stated, but } \\
\text { contact with any suspected chemical } \\
\text { denied }\end{array}$ & $\begin{array}{l}3 \text { years } \\
46 \text { years }\end{array}$ \\
\hline 57 & Alive & $\begin{array}{l}\text { Chemical occupation not stated, but } \\
\text { contact with any suspected sub- } \\
\text { stance denied. However, his work } \\
\text { was in a benzidine shed. }\end{array}$ & 18 years \\
\hline
\end{tabular}

certificates of tumour of the bladder. The seven cases with death certificates of tumour of the bladder from the previous group (Table 10) who had not had contact with benzidine or $\beta$-naphthylamine were combined with this group of 34 , and their ages at death compared with the ages at death in the general population are shown in Fig. 12.

This figure shows that there is a movement towards the younger age groups and the statistical calculations show that, when allowance has been made for the fact that deaths at over the age of 65 may be missing from the chemical workers series because the death certificate might give the occupation as " retired, previous occupation unknown ", the shift is still real and is more than could reasonably be caused by chance sampling errors.

Thus, although it is impossible to say whether or not more tumours have occurred amongst chemical workers who have not had contact with aniline, 


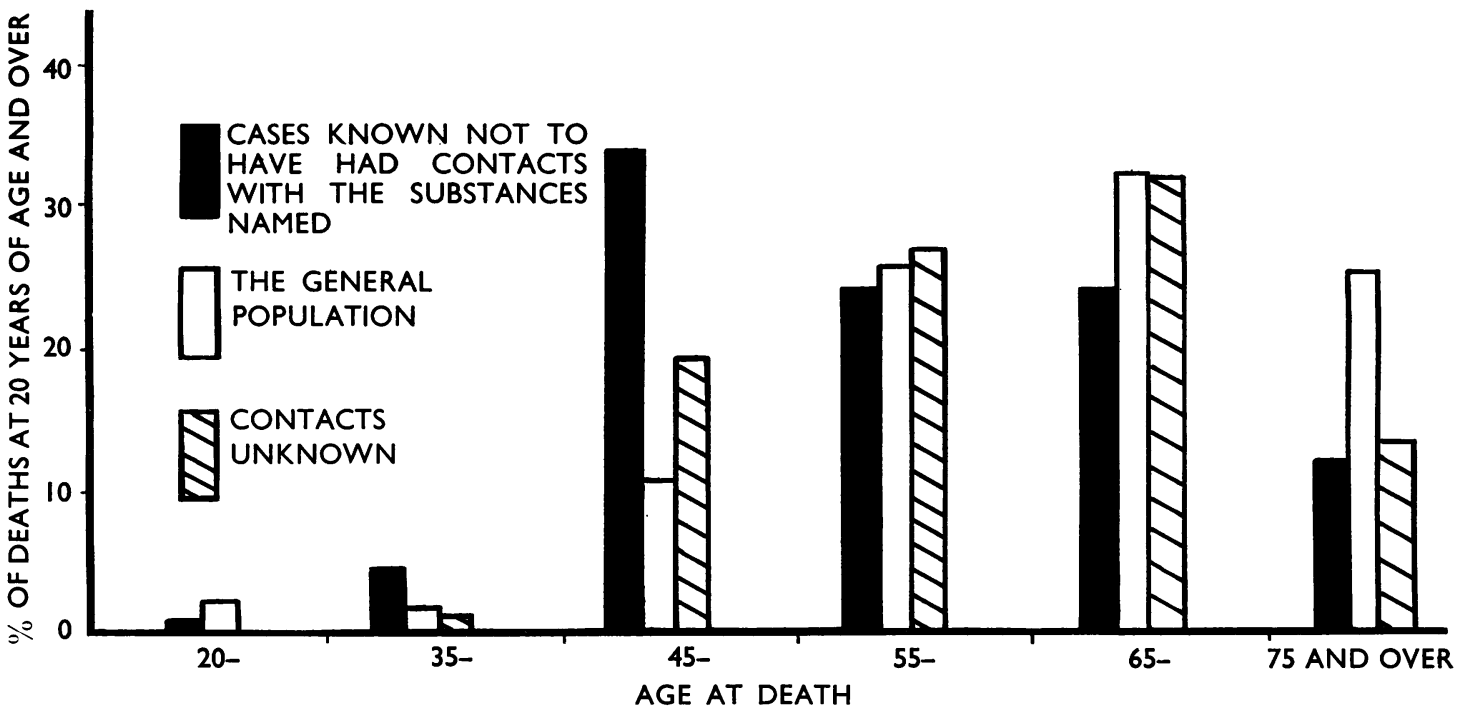

FIG. 12.-The age-distribution at death in 41 cases known not to have had contact with aniline, benzidine, $\alpha$-naphthylamine, or $\beta$-naphthylamine, 81 cases with unknown contacts, and in the general population.

auramine, benzidine, $\alpha$-naphthylamine, or $\beta$-naphthylamine than would be expected if they contracted the disease at the average rate for the general population, it is possible to say that the deaths occurred from bladder tumour at an earlier age than would be expected. This suggests that an environmental risk is operating in this group, but there is no evidence of the causes of the risk.

There now remains for consideration a group of cases whose contacts are unknown. These include 65 men whose employers are unknown, 10 men employed by firms no longer existing, three men employed by firms not members of A.B.C.M., and 11 men amongst the cases from participating firms. Of these 89 cases, 81 have death certificates mentioning tumour of the bladder.

The age distribution at death of these 81 cases is also shown in Fig. 12. Again there is a very slight movement towards the younger age groups, but this is no greater than could reasonably be attributed to chance sampling fluctuations, allowing for the possible loss of cases aged over 65 because of retirement. It is not possible to say whether or not an environmental risk is at work amongst this group.

\section{Discussion}

In general, each result has been discussed as it was achieved. Therefore no further discussion of the foregoing is needed. Certain general topics are however raised, and these are dealt with below.

It does not fall within the scope of this report to suggest alterations in industrial practice. However, it might not be out of place to make some suggestions for future investigation of the risk, so that changes due to better industrial practice can be assessed at an early date.

First, it is apparent that an accurate picture of what is happening can be obtained only from a study of both the population at risk and the cases derived from this population. Therefore it is important that accurate records of men employed should be kept, and their age, date of starting work, and occupational history noted. It would be desirable if records of causes of death of employees or past employees were also kept. It would then be possible for a firm concerned to make an estimate of the number of cases that might occur by the ordinary risk of the disease and the observed number, and so see what processes came under suspicion. The methods for doing this are set out and discussed elsewhere (Case, 1953b) and could be used by either the medical officer or the personnel management department.

Secondly, the number of cases that may be expected in the future makes early diagnosis important. The work of Crabbe (1952) using exfoliative cytology suggests that this method appears to offer advantages over older techniques. It might therefore be advisable to consider how far such a method could be applied in the dyestuffs industry generally.

Thirdly, it would seem desirable at this stage to 
emphasize the need for more experimental work. If trace substances in intermediates play any part in the production of tumours, a possibility suggested by Case and Pearson (1952) and the unpublished work of Case (1948-52), quite different protective measures may be needed from those that would be required to prevent contact with the intermediates themselves. A prerequisite of protection is a knowledge of the forces against which protection is required.

\section{Summary and Conclusions}

This statistical survey demonstrates that contact with benzidine, $\alpha$-naphthylamine, and $\beta$-naphthylamine in either manufacture or use causes many more bladder tumours in workmen so exposed than would appear if no special risk was operating. Furthermore, both the onset of and death from these occupational tumours takes place at a much earlier age than in non-occupational cases.

There is no evidence that aniline causes an increased number of bladder tumours in men who manufacture or handle it. There is, however, some evidence to suggest that the manufacture of magenta and auramine may cause tumours, and further details will be published in this journal later.

There is some evidence that work in the chemical industry which does not involve contact with any of these substances may cause earlier deaths from bladder tumour than occur in the general population, although figures are not available to measure whether a greater number of tumours is produced than would occur in the general population.

$\beta$-Naphthylamine has been the most potent cause of occupational bladder tumours between 1915 and 1951. In those firms which manufacture aniline, benzidine, $\alpha$-naphthylamine or $\beta$-naphthylamine, the ratios of the potencies of $\beta$-naphthylamine, mixed exposures, benzidine, and $\alpha$-naphthylamine in manufacture or use have been respectively $5 \cdot 2$, $2 \cdot 7,1 \cdot 7,1.0$. However, when all the cases expected from this group have appeared, this ratio should change to $3 \cdot 8,2 \cdot 0,1 \cdot 2,1 \cdot 0$. This difference of ratio is due to the different times required for the tumours to become manifest.

The tumours appear after an induction period of an average length of 16 years for $\beta$-naphthylamine and benzidine and 22 years for $\alpha$-naphthylamine. However, tumours may appear in less than two years from the first exposure or after more than 45 years from first exposure. Thus the length of time between the first exposure and the development of a tumour should not be considered as a bar to recognizing the tumour as being of industrial origin.
The average induction time is not appreciably influenced by the severity or duration of the exposure. It therefore appears to be a characteristic of the causal agent. This suggests that it is possible that the $\beta$-naphthylamine content of $\alpha$-naphthylamine is not the sole causative agent in the latter substance unless it is assumed that $\alpha$-naphthylamine could retard the production of $\beta$-naphthylamine tumours.

In the largest group available for study, that is the group of firms which manufacture aniline, benzidine, and either $\alpha$ - or $\beta$-naphthylamine, the final proportion of all workers employed for more than six months who had any contact, in the manufacture or use, with the latter three of these substances was about $20 \%$.

Calculations suggest that, in the absence of any further exposure after 1951, this group of 2,466 men, which has already given rise to 243 cases, may be expected to produce a further 243 cases, making 486 cases in all. This calculation indicates only an approximate expectation, since many relevant conditions may be expected to have altered.

In other words, in this section of the chemical industry (Group I) one in 10 of the men exposed in the way defined above between 1915 and 1950 has already developed bladder tumour, and this figure may be expected to reach one in five before all the men are dead from all causes. The severity of the risk seems to have been mitigated slightly for men employed since 1930, and the data suggest that this comes from a diminution of risk in persons exposed to benzidine and mixed exposures. However, the risk is still such that taking the average post-1930 values, one in six of all men employed in contact with any of these substances may be expected to develop a tumour, whereas before 1930, one in four would be expected to do so. Since these data were collected, the manufacture of $\beta$-naphthylamine has been abandoned in Great Britain, and major alterations in techniques of manufacture and handling of $\alpha$-naphthylamine have been introduced.

The actual risk of developing a tumour is influenced to a small extent by the age at which a man starts work in a hazardous occupation, there being a slightly increased susceptibility in older men. For all practical purposes, however, the age at which he is likely to develop a tumour, if he does so, is almost entirely dependent on the age at which he starts, being on the average 18 years later.

The length of exposure to a hazardous environment affects the chances of a man developing a tumour, but exposures of less than one year to $\beta$-naphthylamine, benzidine, or mixed exposures carry a definite risk. $\alpha$-Naphthylamine requires a 
longer exposure to produce an equivalent effect but too much reliance should not be placed on the absence of any cases with under one year's exposure, since the number of cases that could be expected if a risk is present is very small.
The use of sulphates or hydrochlorides instead of bases does not remove the risk, but there is evidence to suggest that the manufacture of benzidine sulphate followed by conversion to the base may be less hazardous than the direct isolation of the base.

\section{S T A T I S T I CA L A P P E N D I X}

\section{THE COMPLETENESS OF DEATH CERTIFICATION AS BLADDER TUMOUR IN CASES SO DIAGNOSED IN A SAMPLE OF THE GENERAL POPULATION}

Eight hundred and nineteen male patients with bladder tumour notified to us by the cooperating hospitals were found to have died between the years 1936 and 1949.

A complete alphabetical record of all death certificates mentioning tumour of the bladder for all males in England and Wales has been compiled for these years and this enables the certification to be checked. From these data Table Ia was computed.

TABLE Ia

COMPLETENESS OF DEATH CERTIFICATION MENTIONING BLADDER TUMOUR IN HOSPITAL SURVEY DATA

\begin{tabular}{|c|c|c|c|}
\hline Nature of Tumour & $\begin{array}{l}\text { No. of } \\
\text { Cases }\end{array}$ & $\begin{array}{c}\text { No. of Cases } \\
\text { where Death } \\
\text { Certificate } \\
\text { Mentions } \\
\text { Bladder } \\
\text { Tumour }\end{array}$ & $\begin{array}{l}\text { No. of Cases } \\
\text { where Death } \\
\text { Certificate } \\
\text { does not } \\
\text { Mention } \\
\text { Bladder } \\
\text { Tumour }\end{array}$ \\
\hline $\begin{array}{l}\text { Papilloma or benign } \\
\text { tumour of bladder }\end{array}$ & 103 & $47(45 \cdot 6 \%)$ & $56(54 \cdot 4 \%)$ \\
\hline Carcinoma of bladder .. & 716 & $619(86 \cdot 4 \%)$ & $97(13.6 \%)$ \\
\hline Total .. & 819 & $666(81 \cdot 3 \%)$ & $153(18 \cdot 7 \%)$ \\
\hline
\end{tabular}

Preparation and Analysis of the Nominal Roll

Twenty-one firms had provided nominal rolls. In most cases records were obtained from about 1920 onwards. This meant that many men whose names were on the nominal roll were employed before 1920 but were still in employment. If the date of first employment was before 1910 the names were discarded.

The names for each of the three groups of firms were allocated into date-of-entry groups, subdivided into these groups, 1910-1919, 1920-1924, 1925-1929, and so on to $1945-1949$. For computing purposes these men were regarded as having started work in 1915, 1922.5, 1927.5, and so on in five-year intervals until 1947.5.

All the names of men which had been placed on the nominal roll, where the men had been employed by the firm for less than six months, were discarded. Some firms included women's names in the nominal roll, but since the numbers were few, and since death certificates for females were not available, these were not considered in this analysis.
Three firms submitted nominal rolls where information about dates of employment and age were omitted. The numbers concerned, and the groups affected, were as follows : Manufacture of aniline without magenta contact, 142 men between 1929 and 1950 ; mixed exposure, Group I, 44 men between 1915 and 1950 ; mixed exposure, Group II, 140 men between 1924 and 1950. These were allocated as described later.

The men in each date-of-entry group were further subdivided according to their age at entry, using the groupings under 20, 20-29, 30-39, 40-49, 50-59, 60 and over, and age unknown. The lay-out by cells of this type of subdivision is shown in the methods discussed by Case (1953b).

The men whose date of entry was unknown were now allocated to the classification age unknown for each age group in the period covered by the nominal roll of that firm. The allocation to each age group was made by taking the total number of men whose date of entry was known who entered the exposure class concerned after the date of beginning for the unknowns, and finding the percentage entering for each date-of-entry group subsequent to this date. This proportion of the unknowns was allocated to the appropriate age groups.

It had been noted that the distribution of numbers entering in each exposure group was fairly constant for that group from firm to firm, and probably reflected the economic structure of the industry at that date.

The expectation of death certificates mentioning tumour of the bladder, on the hypothesis that these accrue at the mean rate for England and Wales, can now be calculated from the equations described by Case (1953a). The steps used are discussed in detail by Case (1953b). The results of these calculations have been shown in Table 2 (p. 80).

In Group I, the group used for the critical evaluation of the existence of a hazard, the column " $\%$ of expected number derived from incomplete data" is put in to show that part of the expectation was calculated from the men who were allotted to the particular cells by the adjustment already described.

The probabilities are in all cases calculated from the estimate by the use of tables of the Poisson distribution. Where the probability value is on the border-line of 
significance, the expectation derived from incomplete data should be considered in allotting a limit of significance. Thus the "all aniline" probability is not considered significant, only suspicious. The interpretation placed on the Table has been discussed in the report.

\section{Effect of Age of Entry on Incidence of Bladder Tumour}

It is convenient to consider this calculation here, since it is made from the nominal roll subdivided as just described. The analysis makes the assumption that entrants at each age of entry were distributed in equal proportions in each exposure class. This approximation involves only negligible errors. The numbers in each ageof-entry-cell are loaded with the appropriate constants from the 1931 life tables, and the expectation calculated from the observed crude percentage incidence (vide infra) for the pooled data (Table 4).

The mortality loaded figures show that there is an increased incidence in older persons but, since the numbers dealt with are so small, weighting constants for the increased incidence cannot be calculated with sufficient accuracy to be of value. Therefore, for the purposes of this analysis, the assumption will be made that the age of entry has no effect on the incidence of bladder tumour and this unjustified assumption will call for caution in the interpretation of the apparent reduction of risk after 1930 , which will become overestimated.

\section{Ages at Death and at Onset in General Population and in Different Categories of Chemical Workers}

If a comparison between the age at death or onset in the chemical worker groups is to be made with similar data for samples representing the general population, it is necessary either to assume that the age-structure of the population at risk is sufficiently similar to the general population to prevent errors of a magnitude that would invalidate the conclusions or to have a sufficiently detailed knowledge of the population at risk to correct the figures to allow for the difference. In the instances under consideration, the former method is available for all categories of chemical workers, with the reservations to be discussed, and the latter method only in the case of death certificates derived from the nominal roll.

The age distribution of chemical and dyestuffs workers in England and Wales is set out in the Census returns (General Register Office, 1924 and 1934) for 1921 and 1931 and for Great Britain in the One per cent Census Sample (General Register Office, 1952), and these distributions are very similar to the age distribution of all males for the corresponding years. There is no reason for assuming that the dyestuffs division of the chemical industry has a widely different age composition from the broader classification of chemical and dyestuffs worker. The nominal roll itself defines a population at risk which would have a deficiency of older members, but the whole distribution is restored to that of the general population by the inclusion of those people who entered employment before 1910 and who are therefore ignored in the nominal roll.

If, therefore, we take all death certificates found (or all cases found where this is relevant) irrespective of whether they appear on the nominal roll or not, we are sampling from a population at risk similar in age composition to the general population, subject to a limitation that the sample is restricted to ages under 65 , since owing to retirement and a stated occupation of " retired, previous occupation unknown" a bias will be introduced in older age-groups.

Where age of onset has been considered, the sample of the general population used is the Birmingham area. The population of this area is similar in age composition to the population of England and Wales (Padley, 1951).

The complete distribution for deaths in England and Wales for 1921-23, 1930-32 and 1946-49 compounded, for age at onset for Birmingham cases 1936-49, and for the various categories of chemical workers are shown in Table IIa. Table IIa also shows the curtailed distributions employed in the comparisons, obviating the bias discussed above.

In the case of the deaths derived from the nominal roll it is possible, by a series of partial summations of the comparative composite cohort analysis (Case 1953a, b) sum already used to obtain the total expected number, to calculate the exact expected distribution for the population shown in the nominal roll. This expected distribution is also shown in Table IIa, and is not affected by the bias discussed above.

\section{The Induction Time}

The grouped induction times for the Group I cases for each class of exposure, with the mean and standard deviation and the number of cases expected in each group for the pooled data if the distribution for the pooled data is a normal distribution are shown in Table IIIa.

Fig. 4 shows the frequency histogram of the pooled data fitted with the normal curve calculated for the appropriate mean and standard deviation. The distribution for the pooled data is shown to be normal, and a normal distribution around the respective means is assumed for the component exposure classes. Since the parent distribution is normal, and the distribution in each class approximates to normality, the significance of the difference of the means can be assessed by the use of the $t$ test (Student, 1908). The values of $t$ and the corresponding probability figures for the various differences of the means are also given in Table IIIa.

\section{Influence of Severity of Exposure on Induction Times as Measured by Length of Exposure}

There are 281 cases in Group I where both the exposure time and the induction time are known. These have been divided up by exposure time and induction time groups in Table 5. These data may be regarded as consisting of sub-classes, each independent, and each of which should conform to the appropriate segment of the parent normal distribution of induction time if this is independent of the exposure time.

The sub-classes are (1) all the cases where the induction times and the exposure times are co-extensive, to which must be added the 12 cases with exposure time of 20 to 


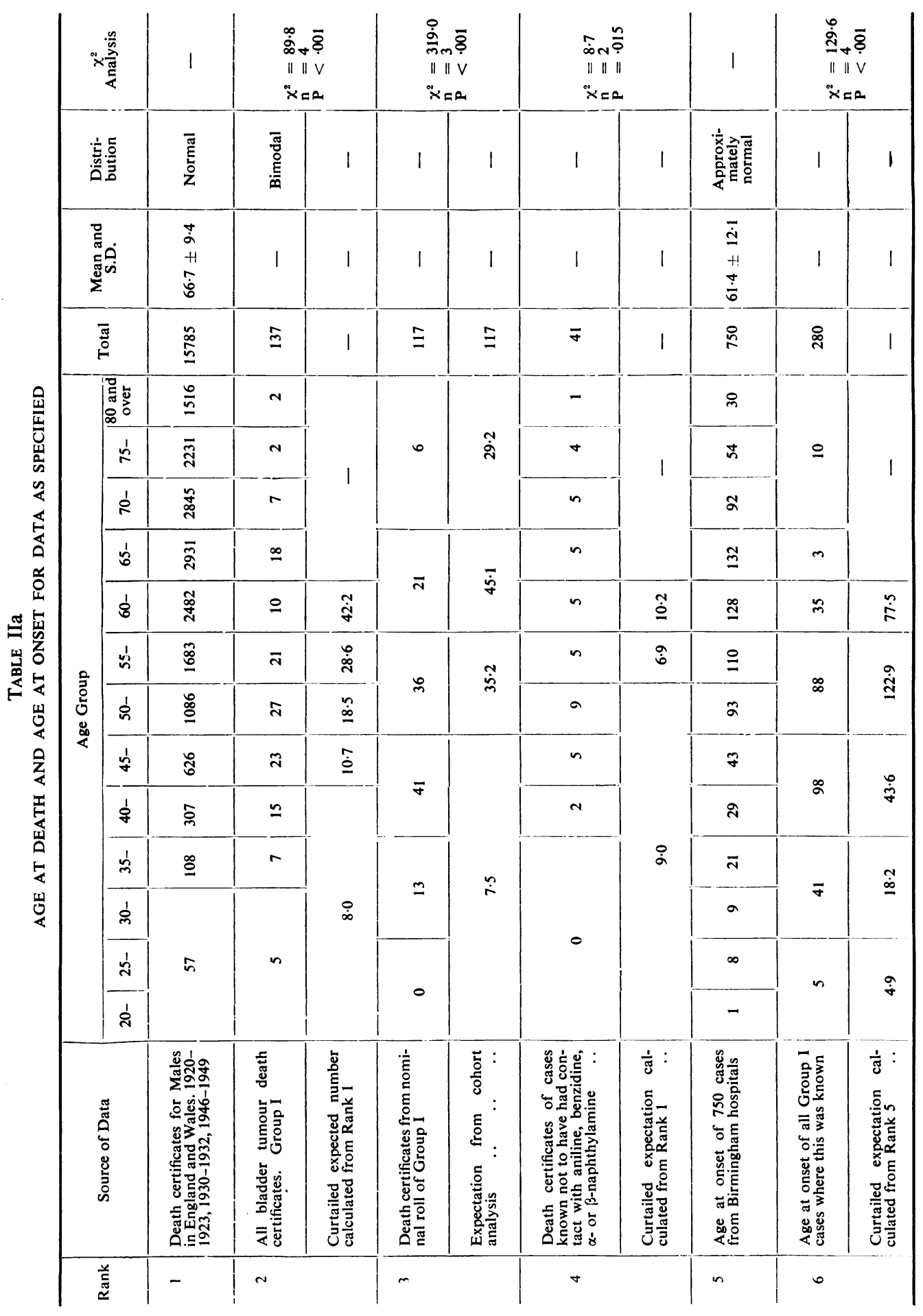


30 years and induction time of over 30 years, since this figure is subject to a constraint which compels it to belong to this sub-class; (2) the complete row of data for each exposure time group excepting the cases mentioned above. These sub-classes all have an induction time in excess of the exposure time and, by definition, no case can have an exposure time greater than the induction time.

The expected numbers are calculated from the appropriate segments of the normal curve $(m=17 \cdot 80$ S.D. $7 \cdot 18$ ) of induction times, assuming a mean age of entry of 34 and adjusting the figures for loss through death from all causes by the English Life Table No. 10 for 1931 (Registrar General, 1945). The difference of the expectation from the observed numbers is assessed by the $\chi^{2}$ technique, using Yates (1934) corrections for continuity where each sub-class has only one degree of freedom. The $\chi^{2}$ is then summed over the whole, and no significant difference is found, and no trend for short exposures to give rise to long induction times is observed. In only one sub-class does the $P$ value fall below 0.05 .

The total expected distribution can then be found by summation (bottom line of table) and this also does not differ significantly from the total observed distribution.

\section{Severity of Incidence of the Disorder in Population at Risk at Different Times}

It is now necessary to study the dynamics of the rate of appearance of cases of bladder tumour by relating the cases to the population at risk from which they were derived. The best sample of the population at risk which is available is the nominal roll. Not all of the cases previously discussed appear on the nominal roll. Some were diagnosed before adequate records were kept, and some were men who had, for various reasons, been omitted from the nominal roll. The allocation of such cases to the nominal roll would cause a bias. Therefore a case of bladder tumour was considered as derived from the nominal roll only if the man's name appeared on the nominal roll as supplied. All other cases are omitted from the following calculations.

The number of men on the nominal roll, and the number of cases derived therefrom for Group I are

TABLE IIIa

DATA RELATING TO THE INDUCTION TIME OF GROUP I CASES

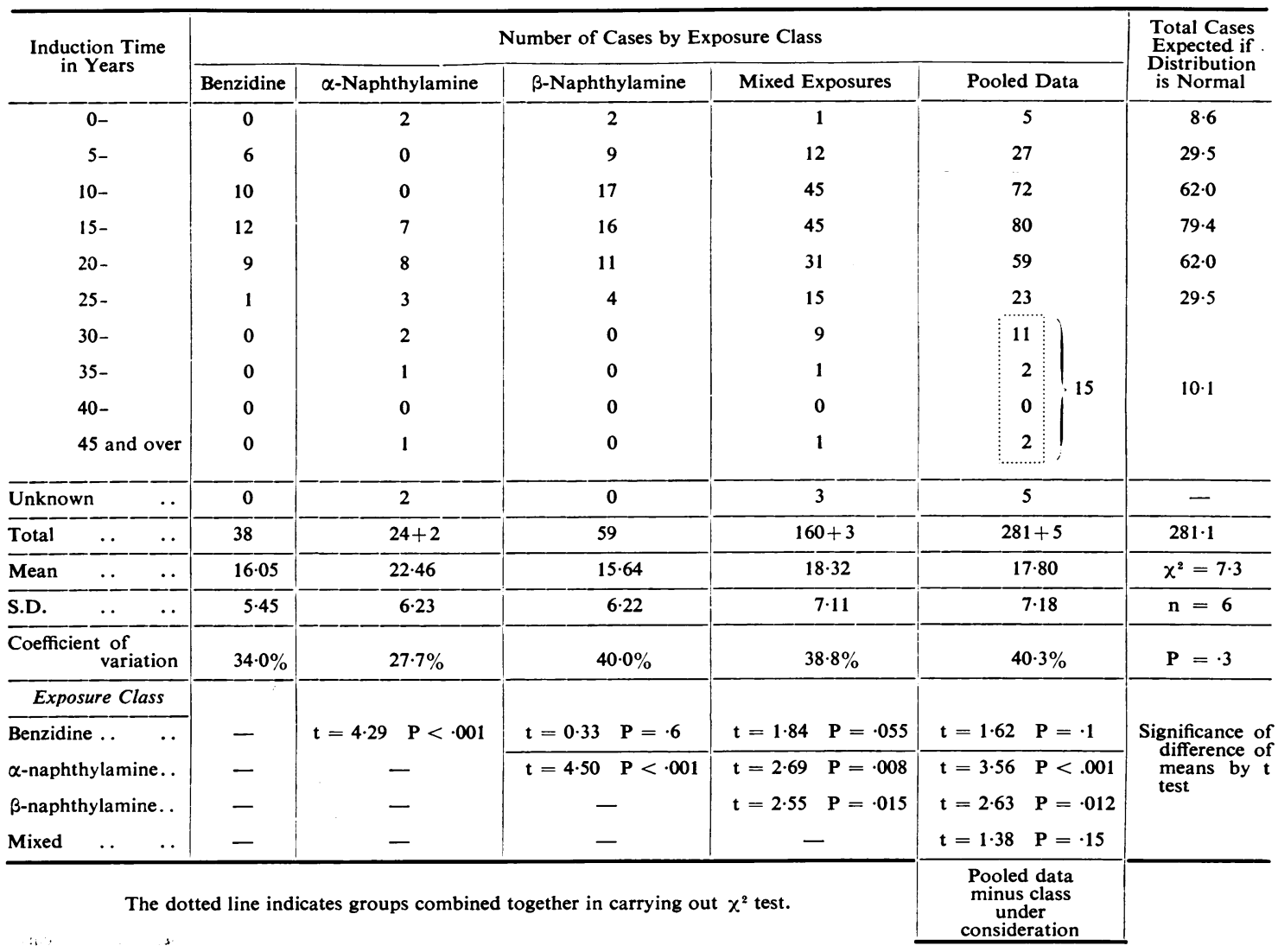


TABLE IVa ADJUSTED NOMINAL ROLL OF GROUP I BY EXPOSURE CLASS AND

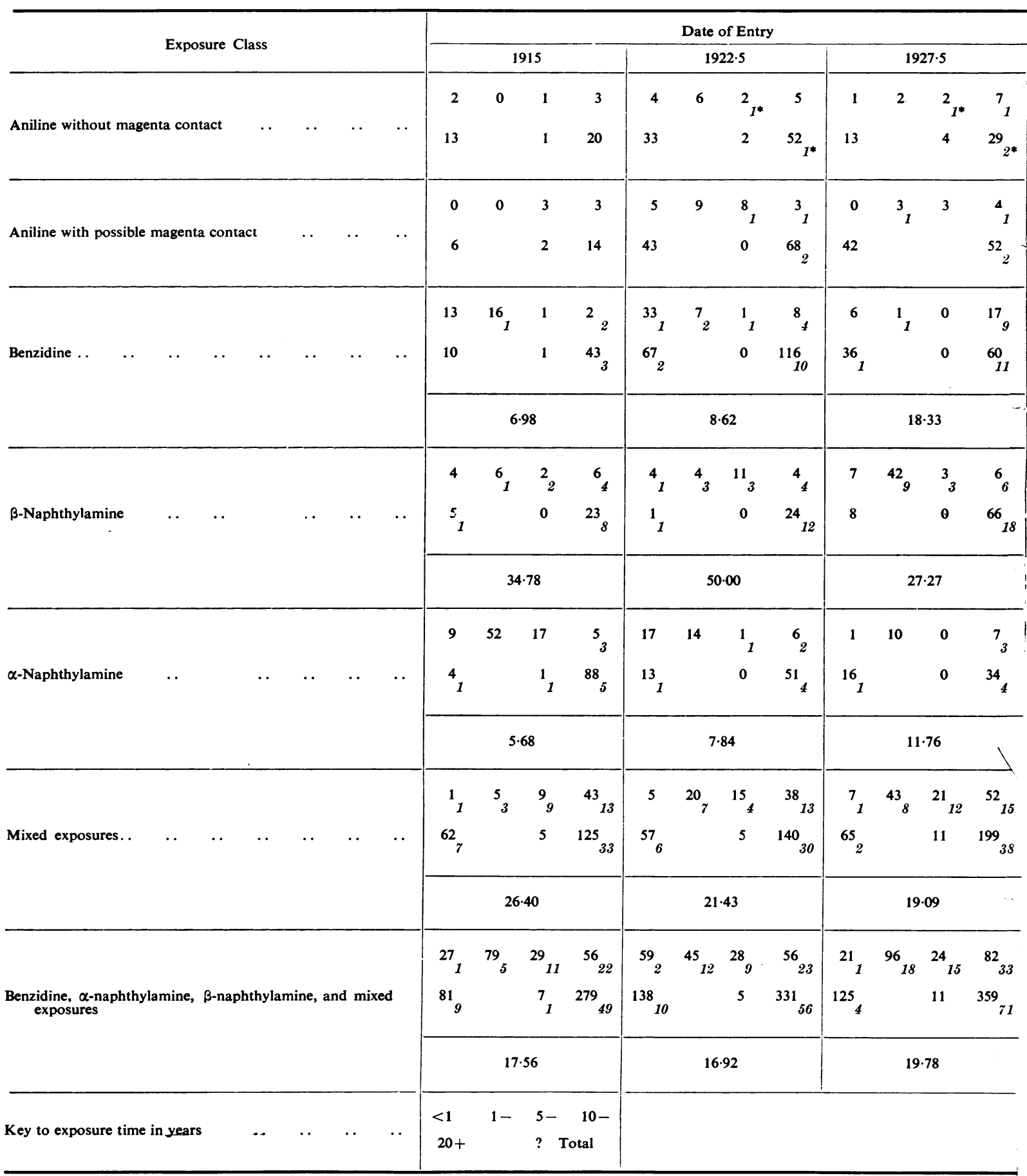


EXPOSURE TIME WITH DERIVED CASES AND CRUDE PERCENTAGE INCIDENCE

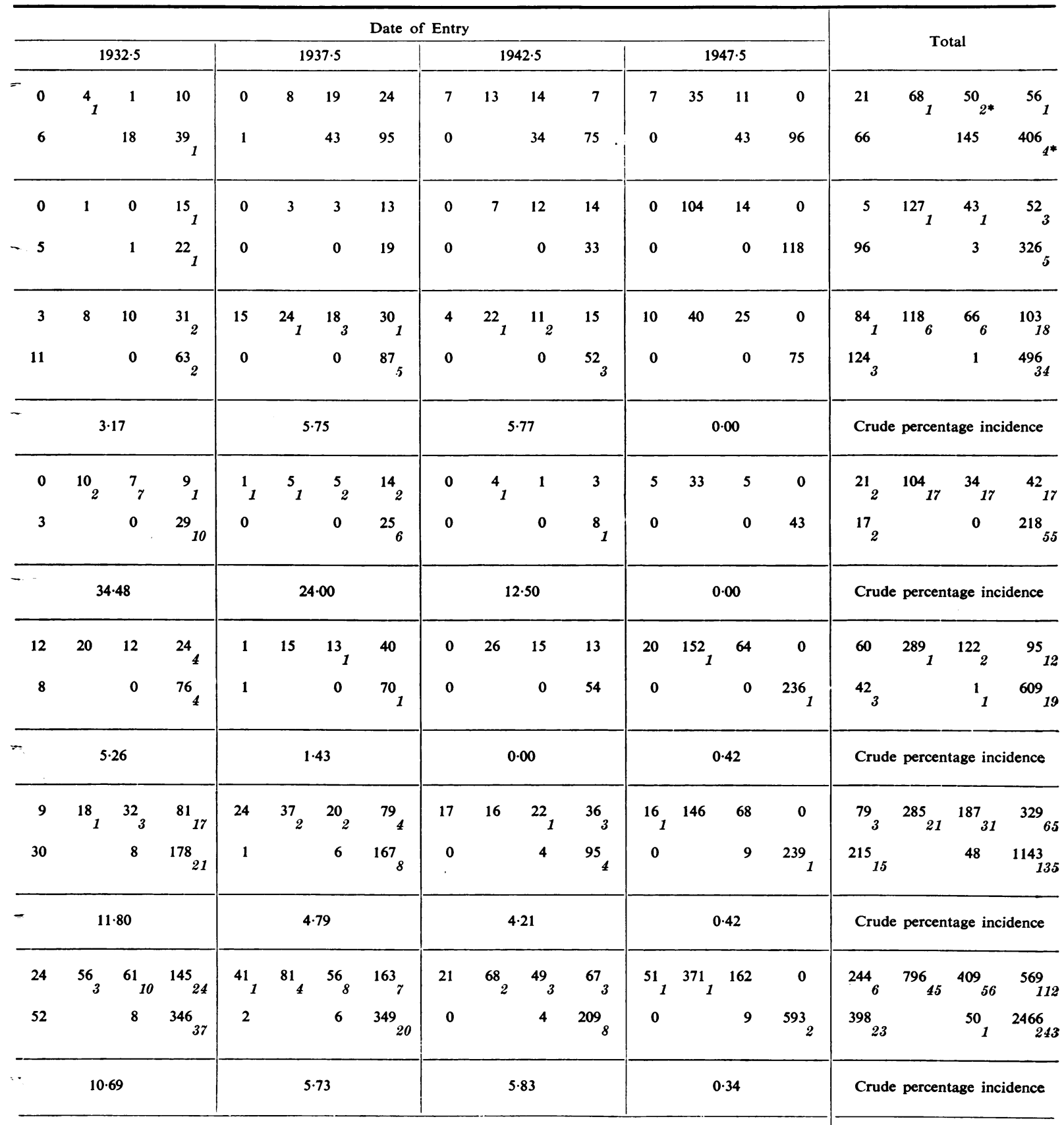


shown in Table IVa. The date of entry is grouped as previously described, and the exposure time into groups of under one year, between one and five years, between five and 10 years, between 10 and 20 years, over 20 years, and not known. The contribution from the last class is very small, being $1.6 \%$ for the nominal roll and one case $(0.4 \%)$ for the other series.

The percentage incidence of bladder tumour that had been attained in each exposure class by February, 1952, can now be calculated from the total for each date-ofentry group. This figure, which makes no allowance for the length of exposure, is referred to as the crude percentage incidence, and is also shown for the exposure classes other than the two aniline classes.

Since the induction times are normally distributed and are uninfluenced by severity of exposure, these crude values should approximate to a cumulative sigmoid normal curve, unless the risk has altered during the years. The values and the calculated normal curve have been shown in Fig. 5. This curve is calculated from the mean and standard deviation of the pooled data and the total number of cases, and has a final incidence of $21 \%$. The goodness of fit of this curve is tested by calculating the number of cases expected in each date-of-entry group. These figures are shown in Table Va.

The cumulative sigmoid normal curve is calculated by finding the regression equation of the probit of the percentage of the final incidence. This equation is derived as follows :

For cumulative sigmoid normal curve, $16 \%$ of the whole area lies to the left of the ordinate one standard deviation below the mean $(\mathrm{m})$. The probit of $16 \%$ is 4.01. The probit at the mean is $5 \cdot 0$. The regression equation of a straight line, $Y=a+b X$ can then be found by $b=(5.00-4.01) / \sigma$

$$
a=5.00-b m
$$

where $\mathrm{Y}=$ probit of percentage of final incidence and $\mathrm{X}=$ time in years since entering exposure.

The regression equations for each class of exposure are thus :

$$
\begin{aligned}
& \begin{array}{ll}
\text { Benzidine } & Y \\
\text { a-Naphthylamine } & \mathbf{Y}=2.08+0.182 \mathrm{X}
\end{array} \\
& a \text {-Naphthylamine } Y=1.43+0.159 \mathrm{X} \\
& \begin{array}{ll}
\beta \text {-Naphthylamine } & Y=2.51+0.159 X \\
\text { Mixed exposures } & Y=2.45+0.139 X
\end{array} \\
& \begin{array}{ll}
\text { Mixed exposures } & \mathbf{Y}=2.45+0.139 X \\
\text { Pooled data } & \mathbf{Y}=2.56+0.138 \mathrm{X}
\end{array}
\end{aligned}
$$

\section{Effect of Length of Exposure}

The effect of length of exposure was investigated as follows :
The crude incidences were calculated by assuming that all exposure times contributed an equal weight to the incidence. This weight may be termed the mean effective exposure. If the percentage number of men on the nominal roll who would have developed tumours at the crude percentage incidence for each date-of-entry group and each class of exposure is found, this may be compared with the number who actually did develop tumours. The summation of the expected number at the relevant crude percentage incidence over all date-of-entry groups for each length of exposure group, compared with a similar summation for the cases actually appearing, will give a measure of the effect of exposure time. This has been shown in Fig. 7.

\section{Adjusting Curves to Remove Effects of Exposure for Different Times at Different Dates}

The effective population at risk can now be calculated from the adjusted nominal roll and these weights for each exposure class. The theoretical percentage incidence is then calculated from this figure and from the number of cases actually found. The figures for the pooled data are then calculated as the sum of the component classes. These effective figures are given in Table VIa.

\section{Measurement of Relative Potency of Each Exposure Class}

The numbers in rank 5 of Table VIa represent a mean potency that may be used as an arbitrary standard by which to measure the potency of each component exposure class. The relative potency of each component exposure class may now be calculated by determining the number of cases that would be expected in that exposure class if the substance had the mean potency, summating over the whole exposure class, and comparing this figure with the number of cases actually found. The numbers expected as percentages of the numbers found are called the relative potencies, and have also been shown in Table 7.

\section{Test of the Internal Consistency of these Data}

These figures have been calculated by using mean figures for the effect of length of exposure, and from a summation over the date-of-entry groups. It is therefore necessary to see that fluctuations of temporal conditions do not invalidate the calculation, and accordingly a test was applied by calculating the numbers that would be expected for each date-of-entry class and each exposure

\begin{tabular}{|c|c|c|c|c|c|c|c|c|c|c|c|}
\hline \multicolumn{3}{|c|}{ Date of Entry } & 1915 & $1922 \cdot 5$ & $1927 \cdot 5$ & $1932 \cdot 5$ & $1937 \cdot 5$ & $1942 \cdot 5$ & $1947 \cdot 5$ & Total & $\begin{array}{l}\text { Difference of } \\
\text { Distribution }\end{array}$ \\
\hline No. expected & .. & .. & $57 \cdot 8$ & $63 \cdot 8$ & $56 \cdot 7$ & $37 \cdot 5$ & $19 \cdot 2$ & $4 \cdot 2$ & $2 \cdot 9$ & $242 \cdot 1$ & $x^{2}=7.1$ \\
\hline No. found. . & .. & .. & 49 & 56 & 71 & 37 & 20 & 8 & 2 & 243 & $\begin{array}{l}\mathrm{n}=5 \\
\mathrm{P}=25\end{array}$ \\
\hline
\end{tabular}

TABLE Va

NO. OF TUMOURS EXPECTED FROM CRUDE PERCENTAGE INCIDENCES FOR POOLED DATA IF OVERALL RISK REMAINS CONSTANT AND NO. FOUND CALCULATED FROM SIGMOID NORMAL CURVE FITTED TO MEAN INDUCTION TIME OF $17.8 \pm 7.18$ YEARS AND 243 CASES

The dotted line indicates groups combined together in carrying out $\chi^{2}$ test. 
TABLE VIa

EFFECTIVE POPULATION AT RISK, NUMBER OF CASES FOUND, AND EFFECTIVE PERCENTAGE INCIDENCE

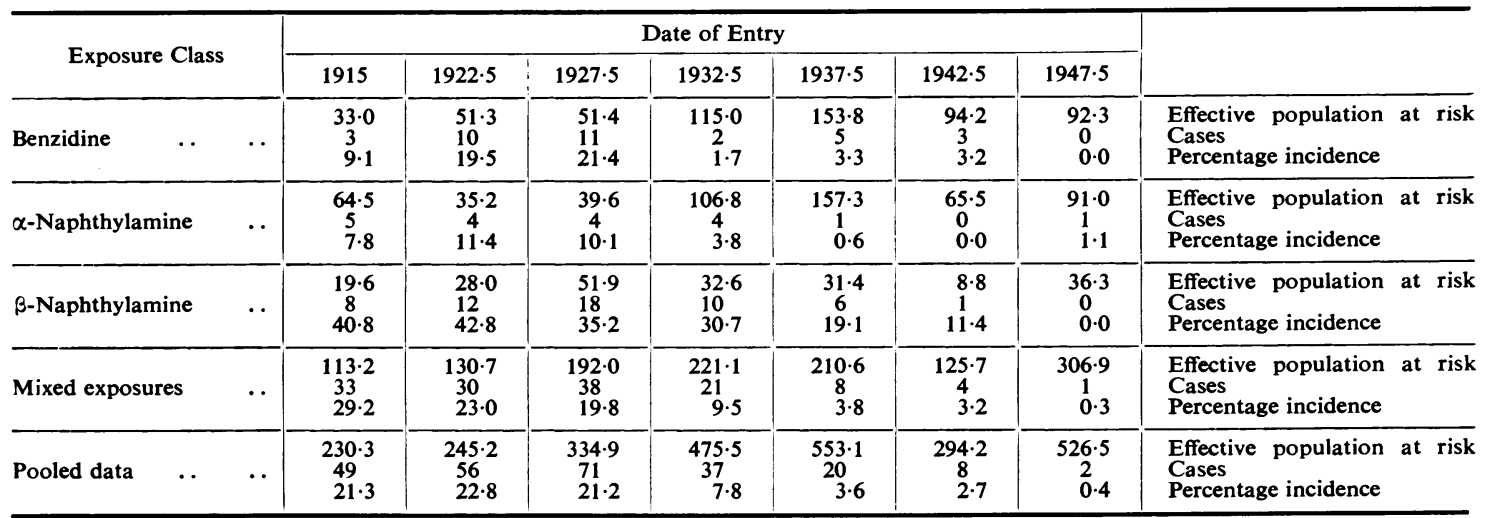

group from the expectation at mean potency multiplied by the relative potency factor, and comparing the distribution of the expectation with the number of cases actually found. The data were found to be internally consistent.

\section{Effect of Temporal Conditions}

The above test of internal consistency dealt only with possible variations of the ratio of potencies, and would not reveal an absolute diminution of potency if these ratios were maintained. Such an absolute diminution would be expected if improvements in technique in more recent years had been effective. This possibility was investigated as follows:

The number of cases expected from the effective population at risk, on the hypothesis that no alteration of risk has occurred, was calculated from the mean value of the appropriate segments of the cumulative sigmoid normal curve corresponding to the year-of-entry groups used. These estimates are weighted with values derived from the Life Tables for Males, England and Wales, 1931 (Registrar General, 1945). The year 1931 is chosen as being the life table most appropriate to the whole period 1915-1950.

These expectations, with the numbers actually found, are shown in Table VIIa.

The changes of conditions and techniques that might be expected to produce a diminution of risk began about 1935. However, the men entering in the group 1930-35 would be affected by these changes since it has been shown that the full effect of exposure is not developed until after more than five years' exposure. Accordingly, these data were considered in two groups, those entering before 1930 , and those entering in or after this date. The table shows that there is an apparent diminution of risk in the exposure classes benzidine and mixed exposures, and in the pooled data, and the $\chi^{2}$ test shows that this is significant. No significant change is found for $\beta$ naphthylamine or $\alpha$-naphthylamine.

This test gives no idea of the magnitude of the reduction of risk, and this was evaluated in the following manner :

The two groups, pre-1930 and post-1930, were regarded

TABLE VIIa

CALCULATED NUMBER OF CASES FOR EACH EXPOSURE CLASS EXPECTED IF RISK HAS REMAINED CONSTANT AND NO. ACTUALLY FOUND

\begin{tabular}{|c|c|c|c|c|c|c|c|c|c|c|c|c|}
\hline $\begin{array}{c}\text { Exposure } \\
\text { Class }\end{array}$ & 1915 & $1922 \cdot 5$ & $1927 \cdot 5$ & $\begin{array}{c}\text { Total } \\
\text { pre- } \\
1930\end{array}$ & $1932 \cdot 5$ & $1937 \cdot 5$ & $1942 \cdot 5$ & $1947 \cdot 5$ & $\begin{array}{l}\text { Total } \\
\text { post- } \\
1930\end{array}$ & Total & & $\begin{array}{c}\chi^{2} \\
\text { Corrected } \\
\text { for } \\
\text { Continuity }\end{array}$ \\
\hline Benzidine & $\begin{array}{l}4 \cdot 2 \\
3\end{array}$ & $10^{6 \cdot 4}$ & 11 & $\begin{array}{l}16 \cdot 7 \\
24\end{array}$ & $\begin{array}{l}9 \cdot 7 \\
2\end{array}$ & $\begin{array}{l}6 \cdot 4 \\
5\end{array}$ & $\frac{1 \cdot 1}{3}$ & $\begin{array}{l}0 \cdot 1 \\
0\end{array}$ & $\begin{array}{l}17 \cdot 3 \\
10\end{array}$ & $\begin{array}{l}34 \cdot 0 \\
34\end{array}$ & $\begin{array}{l}\text { Expected } \\
\text { Found }\end{array}$ & $\stackrel{5 \cdot 441}{P=} \cdot 02$ \\
\hline$\alpha$-Naphthylamine & $\begin{array}{l}7 \cdot 6 \\
5\end{array}$ & $\begin{array}{l}3 \cdot 5 \\
4\end{array}$ & $2 \cdot 7$ & $\begin{array}{l}13 \cdot 8 \\
13\end{array}$ & $\begin{array}{l}3 \cdot 6 \\
4\end{array}$ & $\begin{array}{l}1 \cdot 5 \\
1\end{array}$ & $\begin{array}{l}0 \cdot 1 \\
0\end{array}$ & $\begin{array}{l}0.0 \\
1\end{array}$ & $\begin{array}{l}5 \cdot 2 \\
6\end{array}$ & $\begin{array}{l}19 \cdot 0 \\
19\end{array}$ & $\begin{array}{l}\text { Expected } \\
\text { Found }\end{array}$ & $\begin{array}{l}0.023 \\
\mathbf{P}=\cdot 85\end{array}$ \\
\hline$\beta-N a p h t h y l a m i n e$ & $\begin{array}{l}8 \cdot 3 \\
8\end{array}$ & ${ }_{12}^{11 \cdot 6}$ & $\begin{array}{l}19 \cdot 7 \\
18\end{array}$ & $\begin{array}{l}39 \cdot 6 \\
38\end{array}$ & $\begin{array}{l}9 \cdot 4 \\
10\end{array}$ & $\begin{array}{l}5 \cdot 1 \\
6\end{array}$ & $\begin{array}{l}0.5 \\
1\end{array}$ & $\begin{array}{l}0 \cdot 4 \\
0\end{array}$ & $\begin{array}{l}15 \cdot 4 \\
17\end{array}$ & $\begin{array}{l}55 \cdot 0 \\
55\end{array}$ & $\begin{array}{l}\text { Expected } \\
\text { Found }\end{array}$ & $\begin{array}{l}\mathbf{0} \cdot 110 \\
\mathbf{P}=\cdot 75\end{array}$ \\
\hline Mixed exposures & $\begin{array}{l}25 \cdot 7 \\
33\end{array}$ & $\begin{array}{l}28 \cdot 4 \\
30\end{array}$ & $\begin{array}{l}35 \cdot 2 \\
38\end{array}$ & $\begin{array}{l}89 \cdot 3 \\
101\end{array}$ & $\begin{array}{l}27 \cdot 9 \\
21\end{array}$ & $13 \cdot 5$ & $\begin{array}{l}2 \cdot 7 \\
4\end{array}$ & $\begin{array}{l}1 \cdot 6 \\
1\end{array}$ & $\begin{array}{l}45 \cdot 7 \\
34\end{array}$ & $\begin{array}{l}135.0 \\
135\end{array}$ & $\begin{array}{l}\text { Expected } \\
\text { Found }\end{array}$ & $\begin{array}{l}4 \cdot 140 \\
P=\end{array}=04$ \\
\hline Pooled data & $\begin{array}{l}45 \cdot 8 \\
49\end{array}$ & $\begin{array}{l}49 \cdot 9 \\
56\end{array}$ & $\begin{array}{l}63 \cdot 7 \\
71\end{array}$ & $\begin{array}{l}159 \cdot 4 \\
176\end{array}$ & $\begin{array}{l}50 \cdot 6 \\
37\end{array}$ & $\begin{array}{l}26 \cdot 5 \\
20\end{array}$ & $\begin{array}{l}4 \cdot 4 \\
8\end{array}$ & $2 \cdot 1$ & $\begin{array}{l}83 \cdot 6 \\
67\end{array}$ & $\begin{array}{l}243.0 \\
243\end{array}$ & $\begin{array}{l}\text { Expected } \\
\text { Found }\end{array}$ & $\begin{array}{l}4 \cdot 730 \\
P=\cdot 03\end{array}$ \\
\hline
\end{tabular}


as being segments of two sigmoid cumulative normal curves, weighted for mortality, the curves of each exposure class having the same characteristics but different final incidence figures. The final incidence for the post-1930 group expressed as a percentage of the final incidence of the pre-1930 group gives a measure of the change of risk since 1930 . These calculations are shown in Table VIIIa. The significance is derived from

TABLE VIIIa

EVALUATION OF THE POST-1930 RISK

\begin{tabular}{|c|c|c|c|c|}
\hline \multirow{2}{*}{ Exposure Class } & \multicolumn{2}{|c|}{$\begin{array}{l}\text { Final Percentage } \\
\text { Incidence Expected }\end{array}$} & \multirow{2}{*}{$\begin{array}{l}\text { Post-1930 } \\
\text { Value as } \\
\text { Percentage } \\
\text { of pre-1930 } \\
\text { Value }\end{array}$} & \multirow{2}{*}{$\begin{array}{l}\text { Signifi- } \\
\text { cance }\end{array}$} \\
\hline & Pre-1930 & Post-1930 & & \\
\hline $\begin{array}{l}\text { Benzidine . . } \\
\alpha \text {-Naphthylamine } \\
\beta \text {-Naphthylamine } \\
\text { Mixed exposures } \\
\text { Pooled data }\end{array}$ & $\begin{array}{l}21 \cdot 53 \\
14 \cdot 48 \\
47 \cdot 43 \\
32 \cdot 91 \\
30 \cdot 26\end{array}$ & $\begin{array}{r}8 \cdot 59 \\
17 \cdot 52 \\
56.01 \\
21.93 \\
19.94\end{array}$ & $\begin{array}{r}40 \% \\
118 \% \\
118 \% \\
67 \% \\
66 \%\end{array}$ & $\begin{array}{l}\text { Yes } \\
\text { No } \\
\text { No } \\
\text { Yes } \\
\text { Yes }\end{array}$ \\
\hline
\end{tabular}

the $\chi^{2}$ test previously shown in Table VIIa. There is an overall reduction of risk of about $34 \%$ and this is contributed to by a diminution of risk in the exposure classes benzidine and mixed exposures.

\section{Number of Further Expected Cases in Group I}

The additional cases that may be expected from the nominal roll of the Group I firms, on the assumption that no further contact takes place after 1950 and that the mortality from all causes remains as in 1931, are calculated from the effective populations at risk and the final percentage incidences for pre- or post-1930, according to when the men entered risk. These results have been shown in Table 8. The large number of $\alpha$-naphthylamine cases expected suggests that the potency factors already calculated may have underestimated the potency of this material. They were calculated from cases that have already occurred, and a bias would be introduced because of the longer mean induction time of these cases.

Another method of estimating the relative potency is to calculate the ratios of the final incidences expected at standard (1931) mortality. This has accordingly been done by methods already described. These figures are termed the ultimate relative potencies. These results have been shown in Table 7. These values show that $\alpha$-naphthylamine and mixed exposures have been undervalued, and benzidine and $\beta$-naphthylamine overvalued by the previous method.

\section{Severity of Risk in Groups II and III Firms}

The nominal rolls for Group II and Group III were adjusted and set out as described previously for date of entry and length of exposure. Since the numbers were small, only the pooled data were used. These figures were then corrected for length of exposure, using the factors derived from Group I firms. The expected number of cases was then calculated by multiplying these values by the final incidence $(26.57 \%)$ for the pooled data for Group I and by the appropriate constant for the date of entry, and summating over all date-of-entry groups. The mean age of entry for Group II was 34, and for Group III was 23. The expectation for Group III was therefore adjusted by multiplying by the calculated factor $1 \cdot 110$ to adjust for this. The numbers actually found were expressed as a percentage of these figures to give an estimate of the overall risk in Groups II and III compared with Group I. The results of these calculations have been shown in Table 9.

It is a pleasure to pay tribute to the patience and industry of the member firms who have cooperated so well in the provision of detailed records. Many hospitals have also been of the utmost assistance, and our thanks are due to all these, to the General Register Office, and to the Factory Department of the Ministry of Labour. It is perhaps invidious to cite individuals from amongst all these willing helpers, but the report would not be complete without expressing a particular appreciation of the great help afforded by Dr. Denton Guest of the Huddersfield Royal Infirmary and Miss J. M. Levi of the Birmingham United Hospitals.

\section{REFERENCES}

Association of British Chemical Manufacturers (1953). Papilloma of the Bladder in the Chemical Industry. London.

Baker, K. (1950). Acta Un. int. cancr., 7, 46.

Bonser, G. M. (1943). J. Path. Bact., 55, 1

Bonser, G. M. (1943). J. Path. Bact.,

, Clayson, D. B., and Jull, J. W. (1951). Lancet, 2, 286.

Case, R. A. M. (1953a). Brit. J. prev. soc. Med., 7, 14.

-, (1953b). British Journal of Industrial Medicine, 10, 114. and Pearson, J. T. (1952). Ilè Congres international de Biochimie, Paris, 1952. Résumé des Communications, p. 464 Crabbe, J. G. S. (1952). Brit. med. J., 2, 1072.

General Register Office (1924). Census of England and Wales, 1921. Occupations. H.M.S.O., London.

(1934) Census. of England and Wales, 1931. Occupation Tables. H.M.S.O., London.

(1952). Census 1951 Great Britain. One per cent sample (1952). Census 1951 Great Britain.

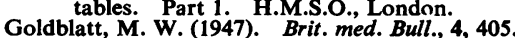

Goldblatt, M. W. (1947). Brit. med. Bull., 4, 405. Henry, S. A., Kennaway, N. M., and Kennaway, E. L. (1931). J. Hyg., Lond., 31, 125.

Hyg., $20,46$.

Müller, A. (1949). Schweiz. med. Wschr., 79, 445.

Padley, R. (1951). City of Birmingham Central Statistical Office,

Annual Abstracts of Statistics, No.1 (1931-1949) p. 7 .
Registrar General (1945). The Registrar General's Decennial Supplement, England and Wales, 1931, Part 1, Life Tables, p. 48. H.M.S.O., London.

Rehn, L. 48. (1895). Ar.. Arh. klin. Chir., 50, 588.

Scott, T. S. (1952). British Journal of Industrial Medicine, 9, 127.

Spitz, S., Maguigan, W. H., and Dobriner, K. (1950). Cancer, 3, 789

Statutory Instrument No. 1740 (1953). H.M.S.O., London.

"Student" (1908). Biometrika, 6, 1.

Yates, F. (1934). J. roy. statist. Soc., Suppl. 1, 217. 